\title{
Seleção de serviços web em composições coreografadas
}

\author{
Patrícia Araújo de Oliveira
}

\author{
DisSERTAÇÃO APRESENTADA \\ $\mathrm{AO}$ \\ Instituto DE MATEMÁticA E EstatísticA \\ DA \\ UNIVERSIDADE DE SÃo PAUlO \\ PARA \\ OBTENÇÃO DO TÍTULO \\ $\mathrm{DE}$ \\ Mestre em CiÊnCIAS \\ Programa: Ciência da Computação \\ Orientador: Prof. Dr. Daniel Macêdo Batista
}

Durante o desenvolvimento deste trabalho a autora recebeu auxílio financeiro da CAPES

São Paulo, Junho de 2014 


\section{Seleção de serviços web em composições coreografadas}

Esta versão da dissertação contém as correções e alterações sugeridas pela Comissão Julgadora durante a defesa da versão original do trabalho, realizada em 30/06/2014. Uma cópia da versão original está disponível no

Instituto de Matemática e Estatística da Universidade de São Paulo.

Comissão Julgadora:

- Prof. Dr. Daniel Macêdo Batista (orientador) - IME-USP

- Prof. Dr. Marco Dimas Gubitoso - IME-USP

- Prof. Dr. Jó Ueyama - ICMC-USP 


\section{Agradecimentos}

Agradeço a Deus que me deu conforto nos momentos difíceis, que me permitiu ter força para superar todas as dificuldades, que me mostrou o caminho nas horas de incertezas e que colocou em minha vida pessoas especiais que foram essenciais nessa etapa da minha vida.

Agradeço aos meus pais, Rose e Osvaldo, que jamais pouparam esforços, e com toda luta e dedicação permitiram que eu pudesse trilhar um caminho que para muitos parecia impossível devido nossa realidade. Obrigada por nunca desistirem! Eu não teria conseguido chegar nem na metade do caminho sem vocês! Obrigada pelo apoio e incentivo! Agradeço também aos meus irmãos, Priscila, Rodrigo e Michelle, que acreditaram junto comigo que era possível e me auxiliaram como puderam nessa etapa. Assim como os demais familiares, Augusto, Cristiane, Leila, Edilson, tia Eugênia, tia Mira (in memoriam), tio Vivi, tia Nazi, Tânia e os demais que mesmo distantes se fizeram presentes e em algum momento não hesitaram em me estender a mão.

Meus sinceros agradecimentos ao Daniel Batista por sua confiança desde o primeiro momento em que aceitou me orientar e por todo aprendizado nesse etapa tão importante em minha vida, o meu muito obrigada!

Agradeço aos meus amigos de Belém, Ivana, Wesley, Gustavo, Erick, Aglaisa, Dani e Aline, por sempre se fazerem presentes, mesmo na distância. Agradeço à Evelin e à Brenda que foram de grande importância em um momento tão difícil que foi a chegada em São Paulo. E para o meu amigo Rafael Gomes, que por várias vezes dedicou seu tempo para me ouvir por horas, pensou junto comigo em muitos pontos importantes deste trabalho, e me permitiu levantar discussões de extrema importância para a dissertação, deixo aqui meu abraço super apertado e minha imensa gratidão.

Durante esse período em São Paulo muitas pessoas passaram em minha vida, deixaram suas marcas e que permitiram que essa etapa fosse mais confortável e feliz. O meu muito obrigada aos amigos Ewerton, Max, Gesner, Gilmar e Gustavo, pela parceria nas disciplinas e pelas muitas risadas em momentos ímpares. Ao amigo Cássio agradeço por todas as vezes que me fez perceber que não estava sozinha. À Tixa, Suelen e Guilherme, agradeço por todos os momentos de conforto, carinho e alegrias. Agradeço também ao Bosco, Oneida e Luiza, cada um com sua particularidade, pelos bons momentos que me proporcionaram. Ao Adilson, Benigno, Larissa, Lilian, Marline, Marcela, Guilherme e Sheldon, agradeço por todos os momentos em que me senti como em uma família. Agradeço ao Daniel Vasconcelos pela pessoa especial que se tornou em minha vida, por todo companheirismo, apoio e carinho.

Por fim, agradeço a todas as pessoas que direta ou indiretamente estiveram comigo e contribuíram em algum momento nesta etapa. Aos amigos do LSI agradeço pelo crescimento profissional e pessoal que pude experimentar junto a eles, em especial, agradeço à Ana Grasi, Irene e Roseli que se tornaram um exemplo de profissionais para mim. Aos amigos do IME, Leo, Cadu e Albert, agradeço por me auxiliarem em etapas importantes da dissertação e à Lu por toda simpatia e ajuda. 


\section{Resumo}

Oliveira, P. A. Seleção de serviços web em composições coreografadas. 2014. 59 f. Dissertação (Mestrado) - Instituto de Matemática e Estatística, Universidade de São Paulo, São Paulo, 2014.

Seleção de serviços em composições distribuídas considera principalmente a qualidade de serviço que atenda requisitos estabelecidos pelo usuário, como por exemplo, preço. No entanto, problemas relacionados a execução de composições de serviços podem ocorrer quando não se considera aspectos relacionados à rede e ao hardware, que afetam diretamente o desempenho da composição. Esse problema se agrava em composições coreografadas, pois a característica descentralizada requer um maior esforço para que essas informações possam ser consideradas em uma perspectiva global. Dessa forma, apesar da descentralização apresentar vantagens, é necessário que requisitos de qualidade de serviço da composição também sejam considerados em coreografias de serviços web para que a escolha de serviços para desempenhar um papel leve em consideração parâmetros importantes que podem afetar no desempenho da composição. Este trabalho apresenta um mecanismo, implementado sobre o framework OpenKnowledge, para selecionar serviços web em ambientes coreografados considerando primeiramente estimativas de atraso, taxa de perda e por fim considera a utilização de outros parâmetros, como utilização de CPU. Os primeiros experimentos em diferentes cenários de rede confirmaram as vantagens da proposta em relação a um seletor de serviços que ignora aspectos relacionados com a rede. Obteve-se ganhos de 20 a $97 \%$ no que diz respeito ao tempo total da execução da coreografia. Em seguida, experimentos inserindo utilização de CPU na escolha dos serviços confirmaram as vantagens de utilização de diferentes parâmetros para seleção de serviços em coreografias.

Palavras-chave: Computação orientada a serviços, composição de serviços web, coreografia de serviços web, seleção de serviços web. 


\section{Abstract}

Oliveira, P. A. Web services selection in choreographed compositions. 2014. 59 f. Master Thesis - Institute of Mathematics and Statistics, University of São Paulo, São Paulo, 2014.

Selection of services in distributed compositions mainly considers the quality of service that meets requirements set by the user, such as price. However, problems related to the execution of service compositions may occur when aspects related to network and hardware, which directly affect the performance of the composition, are not taken in consideration. This problem is aggravated in choreographed compositions because the decentralized feature requires a greater effort so that this information may be considered in a global perspective. Thus, despite the decentralization advantages, it is necessary that the service quality requirements of the composition may also be considered in the choreography of web services so that the choice of services may play a role that takes into account important parameters, which can affect the performance of the composition. This dissertation presents a mechanism, implemented on the OpenKnowledge framework, to select web services in choreographed environments. First, considering delay estimates, loss rate and finally the use of other parameters, such as CPU utilization. The first experiments on different network scenarios confirmed the proposal advantages in relation to a selection mechanism that bypasses aspects of the network. It was obtained gains from $20 \%$ to $97 \%$ considering the total time of execution of the choreography. Then, experiments inserting CPU utilization in the choice of services confirmed the advantages of using different parameters for selection of services in choreography.

Keywords: Service-oriented computing, web services composition, web service choreography, web service selection. 


\section{Sumário}

$\begin{array}{ll}\text { Lista de Abreviaturas } & \text { ix }\end{array}$

Lista de Figuras $\quad$ xi

Lista de Tabelas $\quad$ xiii

1 Introdução $\quad 1$

1.1 Objetivo Geral . . . . . . . . . . . . . . . . . . . . . . . 2

1.2 Objetivos Específicos . . . . . . . . . . . . . . . . . . 2

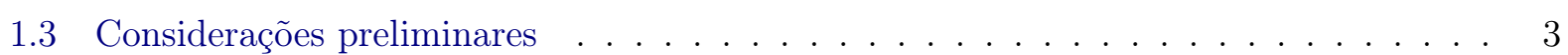

1.4 Organização do trabalho . . . . . . . . . . . . . . . . . . . 4

2 Conceitos básicos $\quad 5$

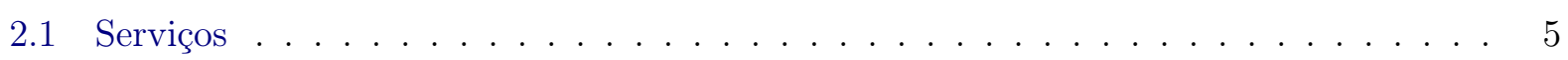

2.1.1 Arquitetura Orientada a Serviços . . . . . . . . . . . . . . . . 5

2.1 .2 Computação Orientada a Serviços . . . . . . . . . . . . . . . . 6

2.2 Composição de serviços web . . . . . . . . . . . . . . . . . . 6

2.2 .1 Orquestração de serviços web . . . . . . . . . . . . . . . . . . . . 7

2.2 .2 Coreografia de serviços web . . . . . . . . . . . . . . . 7

2.3 Coreografia x Orquestração . . . . . . . . . . . . . . . . . . . . 8

3 Framework OpenKnowledge 11

3.1 Arquitetura OK . . . . . . . . . . . . . . . . . . . . . 11

3.2 Lightweight Coordination Calculus (LCC) . . . . . . . . . . . . . . 12

3.2 .1 Papéis . . . . . . . . . . . . . . . . . . . . . 13

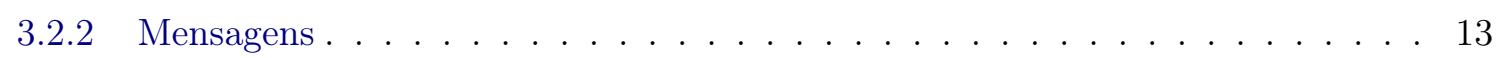

3.2 .3 Restrições . . . . . . . . . . . . . . . . . . . . . . . . . . . . . . 13

3.3 OpenKnowledge Component $(\mathrm{OKC}) \ldots \ldots \ldots \ldots \ldots \ldots \ldots$

3.3.1 Repositório OKC . . . . . . . . . . . . . . . . . . 15

3.3 .2 Gerente de Controle . . . . . . . . . . . . . . . . . . . . 15

3.3 .3 Instância Repositório . . . . . . . . . . . . . . . . . . . . . . . 15

3.3 .4 Coordenadores e Intérpretes . . . . . . . . . . . . . . . . . 16

3.3 .5 Demais Elementos OK . . . . . . . . . . . . . . . . . . 16

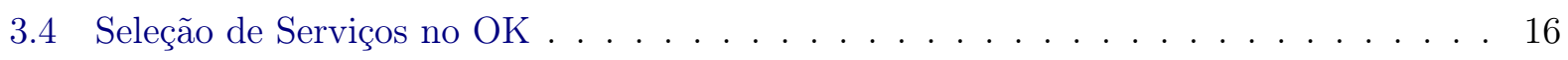

3.4.1 Good enough answer algorithms(GEA) . . . . . . . . . . . . . . 16

3.4 .2 Seleção FIFO . . . . . . . . . . . . . . . . . . . . . . . 17 
5 Seletor de serviços $\quad 23$

5.0 .3 Algoritmos de comparação . . . . . . . . . . . . . . . . . . . . 23

5.0 .4 Algoritmo de pontuação . . . . . . . . . . . . . . . . . . . . 25

5.0 .5 Implementação no $\mathrm{OK} \ldots \ldots \ldots \ldots$. . . . . . . . . . . . 26

6 Experimentos $\quad 29$

6.1 Experimentos Preliminares . . . . . . . . . . . . . . . . . . . . . . . . 29

6.1.1 Atraso como Parâmetro . . . . . . . . . . . . . . . . . . . . . . . 29

6.2 Experimentos em uma Rede Real . . . . . . . . . . . . . . . . . . . . . . 30

6.2.1 Perda como Parâmetro . . . . . . . . . . . . . . . . . . . . . 30

6.2 .2 Perda e Atraso como Parâmetros . . . . . . . . . . . . . . . . . . . . . . 33

6.2.3 Perda, Atraso e CPU como Parâmetros . . . . . . . . . . . . . . . . . . 33

6.3 Discussão dos resultados . . . . . . . . . . . . . . . . . . . . . . . 34

6.4 Selector \& GEA . . . . . . . . . . . . . . . . . . . . . . . 36

7 Conclusões $\quad 39$

7.1 Considerações finais . . . . . . . . . . . . . . . . . . . . . 39

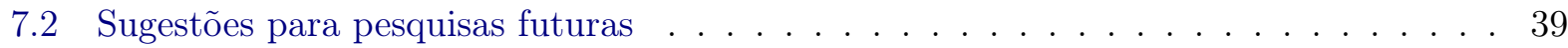

$\begin{array}{ll}\text { Referências Bibliográficas } & 41\end{array}$ 


\section{Lista de Abreviaturas}

CPD Centro de Processamento de Dados

SOC Computação Orientada a Serviços (Service-Oriented Computing)

IaaS Infraestrutura como Serviço (Infrastructure as a Service)

PaaS Plataforma como Serviço (Platform as a Service)

SaaS Software como Serviço (Software as a Service)

QoS Qualidade de Serviço (Quality of Service)

CPU Unidade Central de Processamento (Central Processing Unit)

SOA Arquitetura orientada a Serviços (Service-Oriented Architecture)

P2P Ponto-a-Ponto (Peer-to-Peer)

OK OpenKnowledge

IM Modelo de Interação (Interaction Model)

DDS Serviço de Descoberta Distribuído (Distributed Discovery Service)

OKC OpenKnoledge Component

LCC Lightweight Coordination Calculus

GEA Good Enough Answer Algoritms

FIFO First In, First Out

IP Protocolo de Internet (Internet Protocol)

TC Controle de Tráfego (Traffic Control) 


\section{Lista de Figuras}

2.1 Computação orientada a serviços. Tarefas comuns podem ser facilmente terceirizadas por fornecedores de serviços externos. Traduzida e baseada em [BL06] $\ldots \ldots \ldots$

2.2 Orquestração de Serviços Web. Traduzida e baseada em [GKB12] . . . . . . . . . . . 7

2.3 Coreografia de Serviços Web. Traduzida e baseada em [GKB12] . . . . . . . . . . . 8

3.1 Arquitetura OK. Traduzida e baseada em [BBRW09] . . . . . . . . . . . . . . . . . 12

3.2 Arquitetura GEA. Traduzida e baseada em [GPB07] . . . . . . . . . . . . . . . 17

3.3 Diagrama de Classe GEA. Traduzida e baseada em [GPB07] . . . . . . . . . . . . . 17

5.1 Diagrama Selector. . . . . . . . . . . . . . . . 27

6.1 Tempo de execução da coreografia - local - atraso como parâmetro de seleção . . . 30

6.2 Tempo de execução da coreografia - Máquinas Virtuais - atraso como parâmetro de seleção . . . . . . . . . . . . . . . . . . . . . . . . 31

6.3 Tempo de execução da coreografia - Wifi - perda como parâmetro de seleção ... 32

6.4 Tempo de execução da coreografia - Wifi - perda e perda \& atraso . . . . . . . . . . 33

6.5 Tempo de execução da coreografia Selector $1 \mathrm{MB} \ldots \ldots$. . . . . . . . . . . . . . . . 34

6.6 Tempo de execução da coreografia Selector $2 \mathrm{MB} \ldots \ldots$. . . . . . . . . . . . . . 35

6.7 Tempo de execução da coreografia Selector 3MB f . . . . . . . . . . . . . . . . . 35

6.8 Tempo de execução da coreografia Selector $4 \mathrm{MB} \ldots \ldots$. . . . . . . . . . . . . 36

6.9 Tempo de execução da coreografia Selector $5 \mathrm{MB} \ldots \ldots$. . . . . . . . . . . . 36 


\section{Lista de Tabelas}

4.1 Trabalhos Relacionados . . . . . . . . . . . . . . . . . . . . . . 22

4.2 Critérios de Seleção . . . . . . . . . . . . . . . . . . . . . . . 22

5.1 Categorias Pontuação . . . . . . . . . . . . . . . . . . . 25 


\section{Capítulo 1}

\section{Introdução}

O modelo de computação em nuvem se firmou nos últimos anos como uma alternativa ao modelo tradicional de computação baseado em servidores privados, que são mantidos e operados individualmente pelas empresas. Com isso, diversas classes de serviços, que em geral são chamadas coletivamente de "computação em nuvem", passaram a ser disponibilizadas por provedores de serviços (Centros de Processamento de Dados - CPDs), que estão situados em diferentes locais do mundo.

A partir desse novo paradigma, a internet passou a ser considerada um ambiente fornecedor de diversos serviços que podem ser combinados para a criação de aplicações, proporcionando novas oportunidades para o desenvolvimento de soluções. Dessa forma, o termo Computação Orientada a Serviços (SOC - Service-Oriented Computing) se tornou um conceito pelo qual diferentes recursos são oferecidos como serviços, classificados em diferentes níveis: Infraestrutura como serviço (Infrastructure-as-a-Service - IaaS), Plataforma como serviço (Platform-as-a-Service - PaaS) e Software como serviço (Software-as-a-Service - SaaS), possibilitando o desenvolvimento de aplicações e sistemas complexos [MTDL08]. Através da SOC os serviços passaram a ser a base para construir e prover um desenvolvimento rápido, de baixo custo, de baixo acoplamento e de fácil composição de aplicações heterogêneas distribuídas.

A combinação, ou composição, desses serviços pode acontecer basicamente de duas maneiras: através de orquestração e através de coreografia. A composição de serviços orquestrada é centralizada, ou seja, todo os nós que fornecem os serviços são coordenados a partir de um único nó, que recebe todas as invocações do sistema, o que possibilita uma maior facilidade de controle da composição. A composição de serviços coreografada é descentralizada, ou seja, os nós que fornecem os serviços são independentes e devem ser capazes de atuar de forma autônoma dentro do sistema. Eles se comunicam através de troca de mensagens, por essa razão, coreografias são mais colaborativas do que orquestrações e especificam a composição em perspectiva global.

Orquestrações e coreografias possuem vantagens e desvantagens. No que diz respeito a utilização do meio de transmissão, um modelo de composição de serviços orquestrado pode resultar em uma transferência de dados desnecessária, desperdiçando largura de banda e tornando o coordenador central um gargalo. Por outro lado, um modelo de composição de serviços coreografado, devido a natureza distribuída e colaborativa, é indicado por alguns autores como a melhor alternativa para integração de sistemas - complexos e heterogêneos - em larga escala, construídos sobre nuvens [VIG ${ }^{+}$10, BBRW09], ele vem sendo considerado uma solução ideal para a criação de aplicações complexas por não haver a necessidade de um controle central para a aplicação [GKB12].

Barker et al. (2009) [BBRW09] mostram as vantagens de composições de serviços coreografadas em relação as orquestrações, no que se refere ao fluxo total de dados transferidos pela rede e conclui que coreografias possuem um maior benefício em relação a orquestrações, principalmente quando se tem muitas fontes que enviam dados para um mesmo destino, a diferença da quantidade de dados transferidos via rede, entre orquestrações e coreografias, é de cerca de $50 \%$.

Por outro lado, Guimarães et al. (2012) [GKB12] mostram que implementar um sistema dataintensive com uma composição de serviços coreografada, somente apresenta vantagens se boas escolhas de serviços - com relação à rede - forem feitas, considerando que o processamento não seja 
um gargalo. Por exemplo, se um serviço que transfere dados na ordem de centenas de megabytes é disponibilizado em um computador com baixa largura de banda disponível, e muitas coreografias utilizam esse serviço, ele se tornará um gargalo, da mesma forma que pode acontecer quando há um nó central.

Para garantir a Qualidade de Serviços (QoS - Quality of Service) das aplicações compostas por serviços coreografados, é necessário que sejam consideradas as características distribuídas na composição, ou seja, é necessário considerar que a garantia de QoS da aplicação dependerá do resultado da QoS dos diferentes serviços que a compõem, que, por sua vez, dependerá do estado e da capacidade de diferentes meios de transmissão e de diferentes capacidades de processamento. Porém, a preocupação com a importância da rede e com a capacidade de processamento, no momento de selecionar os serviços que representarão os papéis de uma coreografia, vem sendo pouco abordada na literatura. De forma geral, quando se fala em seleção de serviços web em composições coreografadas, não se considera parâmetros relacionados a comunicação e a execução de serviços.

Os parâmetros mais visados no momento da seleção de serviços web, em geral, são: grau de confiança, custo monetário e tempo de execução para selecionar serviços que desempenharão um determinado papel em uma composição [Lea04, ZBD ${ }^{+}$03, GSM ${ }^{+}$07]. Quando se trata de seleção de serviços web especificamente em composições coreografadas, $\left[\mathrm{BBM}^{+} 08\right.$, HL13] propõem a utilização de parâmetros relacionados ao comportamento, objetivos e confiança dos serviços.

Dessa forma, neste trabalho é proposto um mecanismo de seleção que considera parâmetros de rede e processamento, para selecionar serviços em composições coreografadas, a fim de se obter um melhor desempenho na execução de coreografias. Para isso foi desenvolvido, primeiramente, um mecanismo seletor que analisa o estado da rede, para escolher o serviço que vai fazer parte da coreografia. Em seguida, é proposta a inserção de outros parâmetros para realização da seleção de serviços. Foi inserida, assim, a utilização de CPU (Central Processing Unit) como outro parâmetro para selecionar serviço em composições coreografadas. Por fim, é proposto um mecanismo de múltiplos parâmetros para seleção de serviços em ambientes coreografados.

Neste trabalho é estudado o framework OpenKnowledge (OK) para a implementação do mecanismo de seleção. Ele foi escolhido pois, considerando que sistemas de larga escala são apontados por [ $\mathrm{VIG}^{+} 10$, BBRW09] como mais benéficos para composições coreografadas, implantar serviços de forma independente é uma tarefa árdua. Por essa razão, é muito comum a utilização de ferramentas que auxiliem nesse processo, por ser a solução mais eficaz em comparação ao desenvolvimento de cada serviço de forma independente, em que se implementa individualmente trocas de mensagens, tratamento de erros, entre outros, através de esforço de programação. Além disso, framework OK possui código aberto e estrutura de busca, seleção, coordenação, troca de mensagens, tratamento de erro e todo alicerce que garante uma composição de serviços bem estruturada, o que permitiu a modificação e a implementação da proposta.

\subsection{Objetivo Geral}

O objetivo geral deste trabalho é apresentar a forma pela qual fatores que são atualmente desconsiderados em seleção de serviços web podem afetar no tempo de execução de uma composição coreografada, e propor a utilização de parâmetros que influenciam diretamente nesses fatores, como opções de parâmetros para a seleção de serviços web em composições coreografadas, de maneira a auxiliar na garantia de QoS da aplicação.

\subsection{Objetivos Específicos}

Para alcançar o objetivo geral, foi necessário concluir os seguintes objetivos específicos:

- Estudo do estado da arte;

- Estudo da estrutura e do funcionamento geral do framework OpenKnowledge; 
- Estudo da estrutura e do algoritmo de seleção de serviço do framework OpenKnowledge;

- Implementação do mecanismo utilizando um parâmetro de seleção no framework OpenKnowledge;

- Análise do comportamento do tempo de execução de coreografias que apresentam a característica de transferência de grande fluxo de dados, utilizando um parâmetro de seleção;

- Implementação do mecanismo utilizando dois parâmetros de seleção no framework OpenKnowledge;

- Análise do comportamento do tempo de execução das coreografias que apresentam a característica de transferência de grande fluxo de dados utilizando dois parâmetros de seleção;

- Implementação do mecanismo utilizando mais de dois parâmetros de seleção no framework OpenKnowledge;

- Análise do comportamento do tempo de execução das coreografias que apresentam a característica de transferência de grande fluxo de dados utilizando mais de dois parâmetros de seleção;

- Propor, a partir dos resultados obtidos, uma solução para seleção de serviços web em composições coreografadas, que auxilie na garantia de QoS da aplicação.

\subsection{Considerações preliminares}

Na composição de serviços, cada serviço participante tem uma importante função para que a composição trabalhe de maneira a cumprir o que se propõe. Por essa razão, parâmetros que levem em conta o desempenho - como o aumento do tempo de execução - devem ser considerados, pois um problema em determinado serviço afeta diretamente toda composição. Essa situação é particularmente mais complexa quando se trata de composições coreografadas, nas quais não há um coordenador central que obtenha informações dos nós da composição, o que dificulta uma decisão que garanta um melhor desempenho, tornando mais complexo o controle de QoS de composições coreografadas. Em composições orquestradas, o controle de QoS pode acontecer de forma relativamente simples, já que todos os nós se reportam a um coordenador central, este pode obter facilmente informações e tomar decisões para que o desempenho da composição seja sempre o melhor possível.

A proposta do trabalho de um mecanismo de seleção de serviço em composições coreografadas, implantada no framework OK, se mostrou viável, uma vez que: (1) a utilização de coreografias como forma de compor serviços possui muitas vantagens, principalmente em sistemas de larga escala que apresentem um grande fluxo de dados; (2) a utilização de um grande fluxo de dados em sistemas coreografados pode causar atrasos na composição, caso não seja, por exemplo, considerado o meio de transmissão; (3) para a implementação de sistemas em larga escala, o ideal é a utilização de ferramentas que auxiliem nesse trabalho; (4) o framework OK é uma ferramenta que auxilia a implementação de coreografias e deve ser considerada pela academia, uma vez que possui uma implementação bem estruturada, principalmente no que diz respeito à seleção de serviços.

Como resultado deste trabalho, obteve-se um menor tempo de execução em composições coreografadas, quando comparado a cenários nos quais não há preocupação com o estado da rede utilizada pelo serviço selecionado. O resultado se torna ainda mais evidente, quando há um grande fluxo nas transmissões de dados em cenários com composições coreografadas. O trabalho obteve, também, bons resultados quando passou a considerar outros parâmetros, que podem afetar diretamente o desempenho da composição, como a incapacidade de determinados serviços de processar um grande fluxo de dados. Não obstante, outros parâmetros, como o preço definido pelo usuário, não podem ser descartados no momento da seleção de serviços. Por essa razão, este trabalho tem por finalidade propor um mecanismo de seleção de serviços web em composições coreografadas, que considera múltiplos parâmetros no momento de selecionar o serviço. 
Obteve-se resultados favoráveis na utilização de múltiplos parâmetros de seleção, empregandose o um algoritmo de pontuação para selecionar serviços em coreografias e utilizando do OK para auxiliar a implantação, coordenação, comunicação e seleção desses serviços. Os resultados da utilização de múltiplos parâmetros foram confrontados com um algoritmo de comparação, que utiliza, no máximo, dois parâmetros. Ainda é válido ressaltar que essa proposta, apesar de implementada no OK, não se limita a ele.

\subsection{Organização do trabalho}

No Capítulo 2, são apresentados os conceitos básicos relacionados ao trabalho. No Capítulo 3, é descrito o framework utilizado neste trabalho para a implementação da coreografia. No Capítulo 4, é discutido sobre alguns trabalhos relacionados. No Capítulo 5 é apresentada a proposta de seleção baseada, primeiramente, em parâmetros de rede e, em seguida, é apresentada a proposta de inserção de novos parâmetros de seleção, como o parâmetro de processamento. No Capítulo 6, é mostrado como foram realizados os experimentos e são apresentados os resultados obtidos. Finalmente, no Capítulo 7, são discutidas algumas conclusões obtidas neste trabalho e, são analisadas as vantagens e desvantagens do método proposto. 


\section{Capítulo 2}

\section{Conceitos básicos}

\subsection{Serviços}

Serviços podem ser classificados como um conjunto de componentes que se conectam e interagem entre si através da rede. Esses componentes podem ser servidores ou base de dados que estão espalhados por diversos locais ao redor do mundo.

Em Furtado et al. (2009) [FPA $\left.{ }^{+} 09\right]$ "serviço" é conceituado como sendo módulos de negócio ou funcionalidades das aplicações que são invocados por mensagens e possuem interfaces expostas. Um sistema bancário pode ser considerado como um exemplo de utilização de diferentes serviços. Há serviço de nomes e endereços, serviço de abertura de conta, serviço de balanço de contas, serviço de depósitos, etc. Esses serviços correspondem a recursos de software desenvolvidos uma linguagem de programação e proveem funcionalidades, padrões do negócio, independentes do estado ou contexto de outros serviços [Erl04] e são disponibilizados por provedores de serviços.

O fornecimento de serviços pode ser classificado em diferentes níveis: Infraestrutura como serviço (IaaS -Infrastructure as a Service), que é a possibilidade de utilizar a infraestrutura disponibilizada por um servidor como serviço, por exemplo, criação e geração de máquinas virtuais na nuvem; Plataforma como serviço (PaaS - Platform as a Service) é a possibilidade de implantação transparente de projetos; e Software como serviço (SaaS -Software as a Service) é a utilização de aplicativos que são acessados e utilizados diretamente pelo usuário final através da rede.

\subsubsection{Arquitetura Orientada a Serviços}

A Internet passou a ser um mercado global de colaboração de serviços interconectados, onde usuários podem acessar e utilizar esses serviços disponibilizados por provedores de serviços. Dessa forma, o serviço se tornou o bloco básico para o desenvolvimento em que se pode considerar a Internet como um ambiente fornecedor de diversos serviços, que podem ser combinados para a criação de aplicações. Para isso, é necessário uma arquitetura que oriente a utilização desses serviços. A arquitetura orientada a serviços (SOA - Service Oriented Architecture) é um modelo arquitetural capaz de guiar o desenvolvimento de aplicação baseadas em serviços e desse modo integrar diferentes serviços em um ambiente distribuído. Com isso é possível utilizar, organizar e acessar os diversos serviços disponíveis, independente da tecnologia ou plataforma utilizada, até mesmo sistemas legados.

Segundo Marks e Bell (2006) [MB06], uma abordagem orientada a serviços requer mais disciplina e planejamento, entretanto, o retorno de investimento é elevado. Na SOA, não importa como o serviço foi implementado e sim se ele responde adequadamente as requisições solicitadas, o que significa que o serviço precisa ser seguro e confiável. Esta abordagem de arquitetura é muito útil quando vários aplicativos são executados com tecnologias e plataformas diferentes, e precisam se comunicar uns com os outros. Desta forma, as organizações tem a possibilidade de combinar serviços para realizar transações comerciais com mínimo esforço de programação [BL06]. Serviços web é uma tecnologia de implementação para a realização da promessa de SOA de compartilhamento máximo 
de serviço, reutilização e interoperabilidade [Kre03]. Serviços web e SOA reduzem a complexidade de aplicativos empresariais por definir interfaces de serviço de forma inequívoca e transparente [PVDH07].

\subsubsection{Computação Orientada a Serviços}

A utilização de serviços como elementos fundamentais para o desenvolvimento de aplicações é chamada de Computação Orientada a Serviços (SOC - Service Oriented Computing). Para construir o modelo de serviço SOC utiliza SOA, que reorganiza as aplicações de software em um conjunto de serviços que interagem. Dessa forma, SOC utiliza serviços como base para construir e suportar um desenvolvimento rápido, de baixo custo, de baixo acoplamento e de fácil composição de aplicações heterogêneas distribuídas [MTDL08]. Os serviços são oferecidos por prestadores de serviços, ou seja, organizações que adquirem as implementações de serviços, fornecem descrições de seus serviços e prestam apoio técnico. Devido a interoperabilidade de SOC, as empresas têm a possibilidade de compor processos de negócios e integrar diferentes sistemas de informação para permitir a cooperação ad hoc entre diversos parceiros. Assim, SOC reinventa a maneira como as organizações trabalham em conjunto: tarefas comuns em um processo de negócio podem ser facilmente terceirizadas, favorecendo o desempenho [BL06]. A Figura 2.1 mostra um exemplo simples de seleção e composição de serviços.

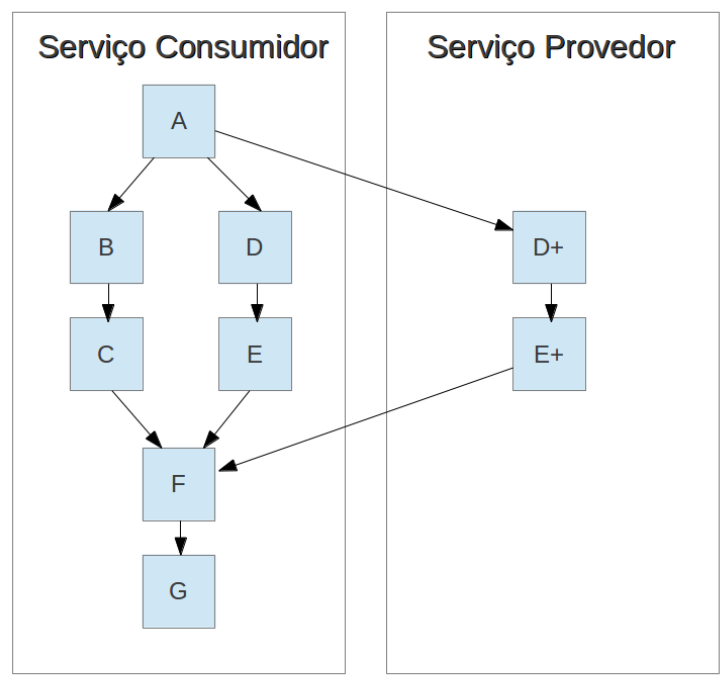

Figura 2.1: Computação orientada a serviços. Tarefas comuns podem ser facilmente terceirizadas por fornecedores de serviços externos. Traduzida e baseada em [BL06]

\subsection{Composição de serviços web}

A integração de serviços web e o aproveitamento dos benefício de SOA somente alcançam seu real potencial com a utilização de mecanismos que tornem possíveis interações entre dois ou mais serviços que permitam a realização de interações mais complexas [MF07]. Os principais mecanismos de integração e composição de serviços conhecidos são através de orquestrações e coreografias, que se distinguem basicamente pela centralização do primeiro e a descentralização de segundo. Centralização e descentralização nesse caso se entende como a forma em que acontece a composição dos serviços em cada um dos casos. Ambas abordagens possuem vantagens e desvantagens, como veremos a seguir. 


\subsubsection{Orquestração de serviços web}

Orquestrações definem uma perspectiva centralizada para a composição de serviços, onde todos os nós que fornecem serviços são entendidos a partir de um único nó. Todas as invocações a serviços passam por esse nó que coordena o sistema e os serviços web são compostos em um único processo de negócio executável [Pel03]. Assim, o orquestrador (nó central) representa o processo sob uma perspectiva global e coordena o fluxo de informações entre os serviços. As principais vantagens da orquestração são: capacidade de fácil adaptação de um serviço, ou um conjunto de serviços, aos requisitos do sistema [DKB08] e facilidade de controle da composição como um todo, uma vez que a composição se comunica através de único ponto. A Figura 2.2 mostra um exemplo de orquestração de serviços web, onde um orquestrador recebe a solicitação de um cliente (1), envia as requisições $(1.1,1.2$ e 1.3) para os serviços, recebe o retorno $(R)$ de todas as requisições e envia a resposta $(R)$ ao cliente.

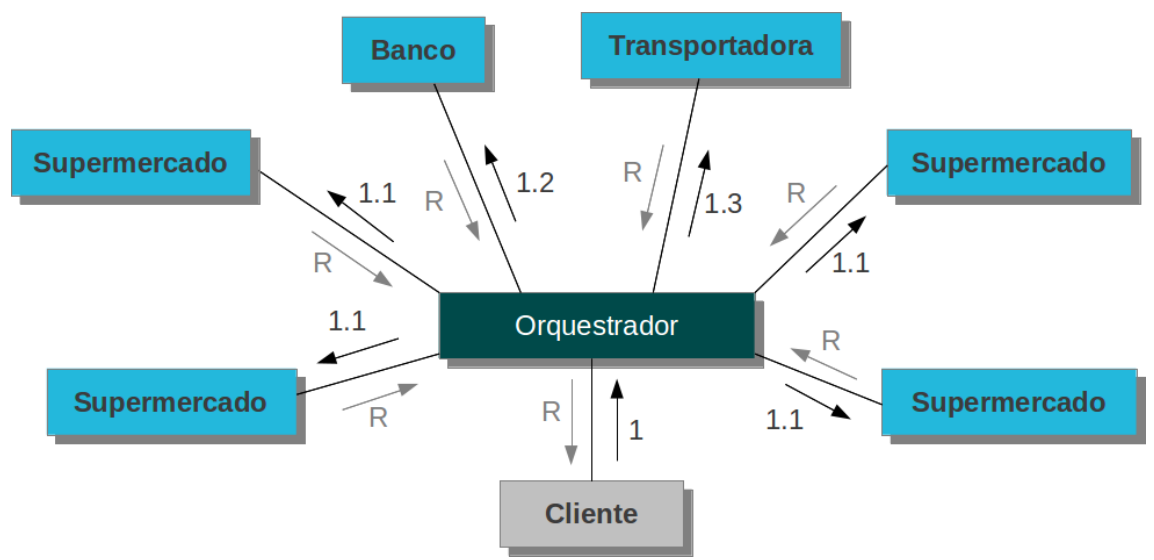

Figura 2.2: Orquestração de Serviços Web. Traduzida e baseada em [GKB12]

Na orquestração, os serviços não têm ciência que estão envolvidos em um nível de aplicação mais alto e, portanto, não precisam de nenhuma alteração pré-determinada. Serviços web orquestrados são descritos a partir da visão de um simples participante, que pode ser outro serviço web.

\subsubsection{Coreografia de serviços web}

Coreografias, diferente de orquestrações, são geralmente mais colaborativas pois representam uma abordagem distribuída para composição de serviços através de uma perspectiva descentralizada, que possui uma visão global do sistema. Cada serviço envolvido em uma coreografia desempenha um papel durante uma interação, esse papel especifica o comportamento a ser seguido por cada serviço durante a execução da coreografia. Dessa forma, entende-se a coreografia como uma interação colaborativa. A Figura 2.3 mostra um exemplo de coreografia de serviços web, onde um cliente faz um solicitação, um agente intermediário a envia para todos os serviços de primeiro nível (1.1), que por sua vez se comunicam com os demais serviços (1.2 e 1.3); os retornos das requisições são enviados diretamente para os serviços solicitantes, que processam e retornam a resposta para o agente intermediário responder ao cliente.

Coreografias são descritas a partir de interações ponto-a-ponto (P2P) entre os serviços existentes, portanto coreografia não depende de um coordenador central. Um modelo de coreografia descreve colaborações de múltiplas partes e foca em mensagens de troca, cada serviço web envolvido sabe exatamente quando executar sua operação e com quem interagir [BBRW09]. Quando uma coreografia é iniciada, não há um nó participante que coordena a interação, cada papel é alocado baseado em mensagens especificadas em um modelo global e cada serviço participante sabe quando e com quem se comunicar [BBRW09]. Uma especificação de uma coreografia descreve apenas as mensagens que devem ser trocadas entre as partes envolvidas, sem definir como os papéis são implementados $\left[\mathrm{HXZ}^{+} 06\right]$ ao contrário de orquestrações, onde as interações entre serviços são especificadas sob a perspectiva do orquestrador. 


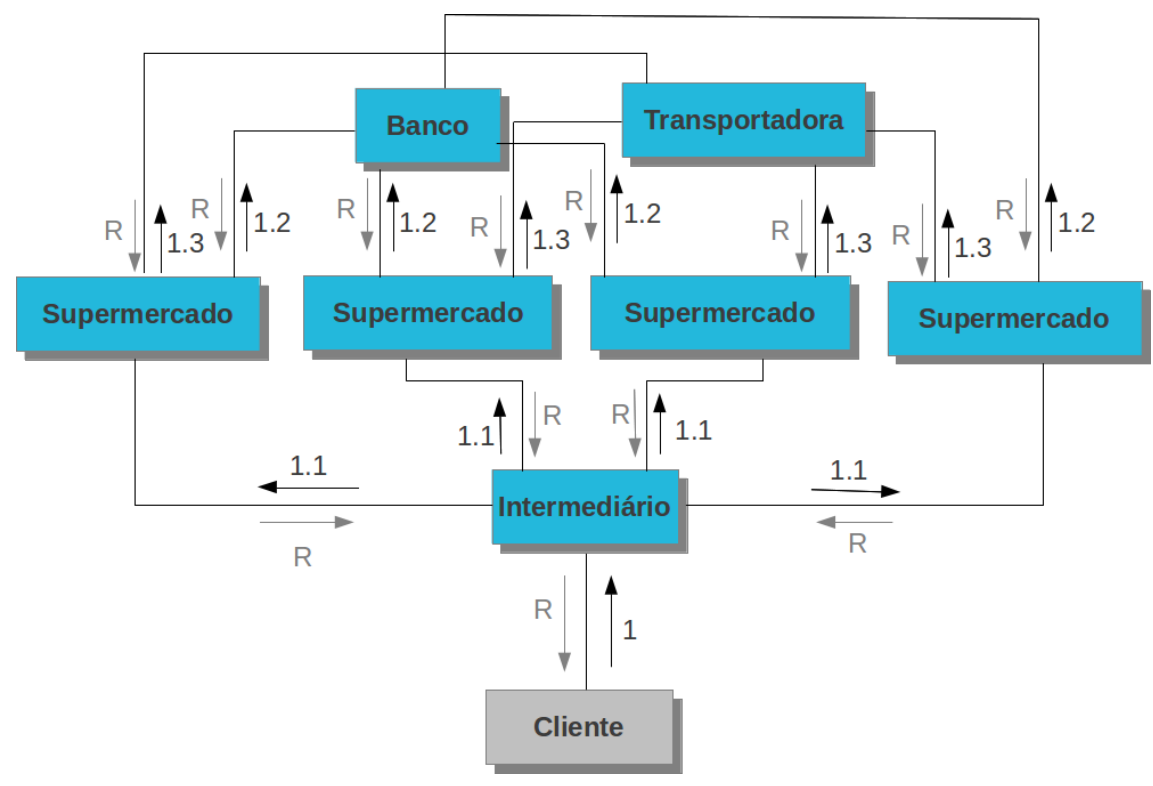

Figura 2.3: Coreografia de Serviços Web. Traduzida e baseada em [GKB12]

Coreografias podem ser executadas através de orquestrações distribuídas [ARDS $\left.{ }^{+} 11\right]$, onde cada orquestração pode ser associada a um papel, dessa forma várias orquestrações serão responsáveis por diferentes partes da coreografia sem existir uma entidade central que armazena o estado global da interação.

A principal vantagem da coreografia diante da orquestração se dá devido ao fato de que a orquestrações possuem o controle centralizado. Assim o nó central é um ponto único de falha. Além disso, arquiteturas centralizadas, em geral, tem problemas de escalabilidade, conectividade (em redes de grande escala), adaptabilidade e configurabilidade. Dessa forma, coreografias tentam resolver essas limitações distribuindo as responsabilidades [FK10]. Em uma coreografia cada serviço participante deve saber quando atuar, com quais outros serviços deve interagir, quais operações deve executar, quais mensagens deve trocar e qual o momento adequado para essa troca de mensagens.

\subsection{Coreografia x Orquestração}

Segundo Barker et al. (2009) [BBRW09] apesar de coreografia ser um conceito estabelecido, ela é uma arquitetura bem menos estudada e implementada do que orquestração. Na prática, os processos de projeto e infraestrutura de execução de modelos de coreografia são inerentemente mais complexos de que os de orquestração. O controle descentralizado traz um novo conjunto de desafios que são o resultado da troca de mensagens entre distribuições assíncronas e processos simultâneos. No entanto, apesar de mais complexa, existe uma série de argumentos favoráveis para a sua adoção.

De uma perspectiva de projeto de software, a orquestração é adequada quando o objetivo é a construção de serviços individuais ou de serviços que formam uma aplicação. No entanto, durante as fases iniciais de projeto, a ênfase não recai sobre a construção de serviços individuais e sim sobre a forma como grupos de serviços trabalham em conjunto, através da identificação de potenciais serviços a fim de compreender e analisar suas interações. Nesse caso, coreografias tratam melhor a comunicação entre serviços do que orquestrações, que atribui esta responsabilidade para um único ponto. Além disso, a coreografia é uma forma de descrever as relações entre os serviços ponto-a-ponto através de uma colaboração global, sem a necessidade de orquestração em tudo. Cada serviço tem um papel predefinido e pré-acordado na coreografia. No entanto, uma orquestração tem um maior controle por coordenar todos os serviços. Finalmente, o controle centralizado através de um mecanismo de orquestração é uma solução válida para cenários encontrados em e-Commerce, onde as quantidades relativamente pequenas de dados intermediários (ou seja, quando a saída de uma chamada de serviço é diretamente usado como entrada para outra, sem nenhuma alteração) 
são movidos entre serviços. No entanto, serviços centralizados fazem menos sentido quando se lida com fluxos centrados em dados (GBs/TB), comuns a aplicações científicas. Passando de grandes quantidades de dados intermediários através de uma orquestração, resultando em uma grande quantidade de transferência de dados e de desperdício de largura de banda, causando uma sobrecarga e diminuindo o desempenho do sistema como um todo. 


\section{Capítulo 3}

\section{Framework OpenKnowledge}

Ferramentas que auxiliem na implementação de coreografias levam vantagens em relação a implementação de serviços de forma independente, pois possibilitam a utilização de estruturas preestabelecidas, auxiliando na economia de tempo de programação. Dessa forma, optamos pelo framework OpenKnowledge (OK) que é um sistema totalmente distribuído usando a tecnologia P2P, onde é possível publicar fluxos de tarefas por meio de linguagens, além de registrar e publicar serviços web que poderão interagir entre si, ele se mostrou viável na coordenação e seleção de serviços. OK é um framework que fornece uma camada de serviços e aplicações que pode ser usada para facilitar a implementação de coreografias e é utilizado juntamente LCC (Lightweight Coordination Calculus) que é uma linguagem que pode ser utilizada para descrever formalmente coreografias.

\subsection{Arquitetura OK}

O sistema OpenKnowledge tem uma arquitetura P2P, onde cada serviço autônomo compartilha um pedaço comum de software que chamamos de Kernel OK. A Figura 3.1 mostra a arquitetura do Kernel OK, onde os principais elementos são:

- Modelo de Interação (Interaction Model - IM);

- Distributed Discovery Service - DDS;

- OpenKnowledge Component - OKC;

- Serviço (S1, S2, S3, S4 ...);

- Papel (pa, pb, pc, pd, pe, pf, pg ...).

O IM é uma especificação formal escrita em uma linguagem concebida para essa finalidade. IMs descrevem papéis e definem as interações entre eles. IMs também especificam mensagens de interações entre serviços, com as restrições relativas à sua execução. As mensagens são enviadas ou recebidas pelos serviços se as restrições de enviar ou receber possuírem ações que possam ser satisfeitas. Isso significa que toda interação tentará satisfazer a restrição de cada mensagem. Se as restrições podem ser satisfeitas, a interação pode ir em frente, caso contrário, deve retroceder para encontrar um caminho alternativo no IM cujas restrições sejam satisfatórias.

Modelos de interação são publicados no DDS, com uma descrição baseada em palavras-chave [KS]. Um serviço que deseja executar algum papel, procura por modelos de interação publicados através do envio de uma consulta de palavra-chave ao DDS. O DDS consulta os modelos de interação publicados e envia de volta uma lista ao serviço. O serviço, em seguida, avalia os requisitos do modelo de interação em relação sua capacidade de executar o papel. Se for correspondente, o serviço irá enviar de volta ao DDS a inscrição a um dos papéis do modelo de interação, anunciando a sua intenção de participar de uma ou mais interações. Capacidades de serviços são fornecidos pelos OKCs, que veremos com mais detalhes na seção 3.3. A Figura 3.1 mostra um exemplo do 


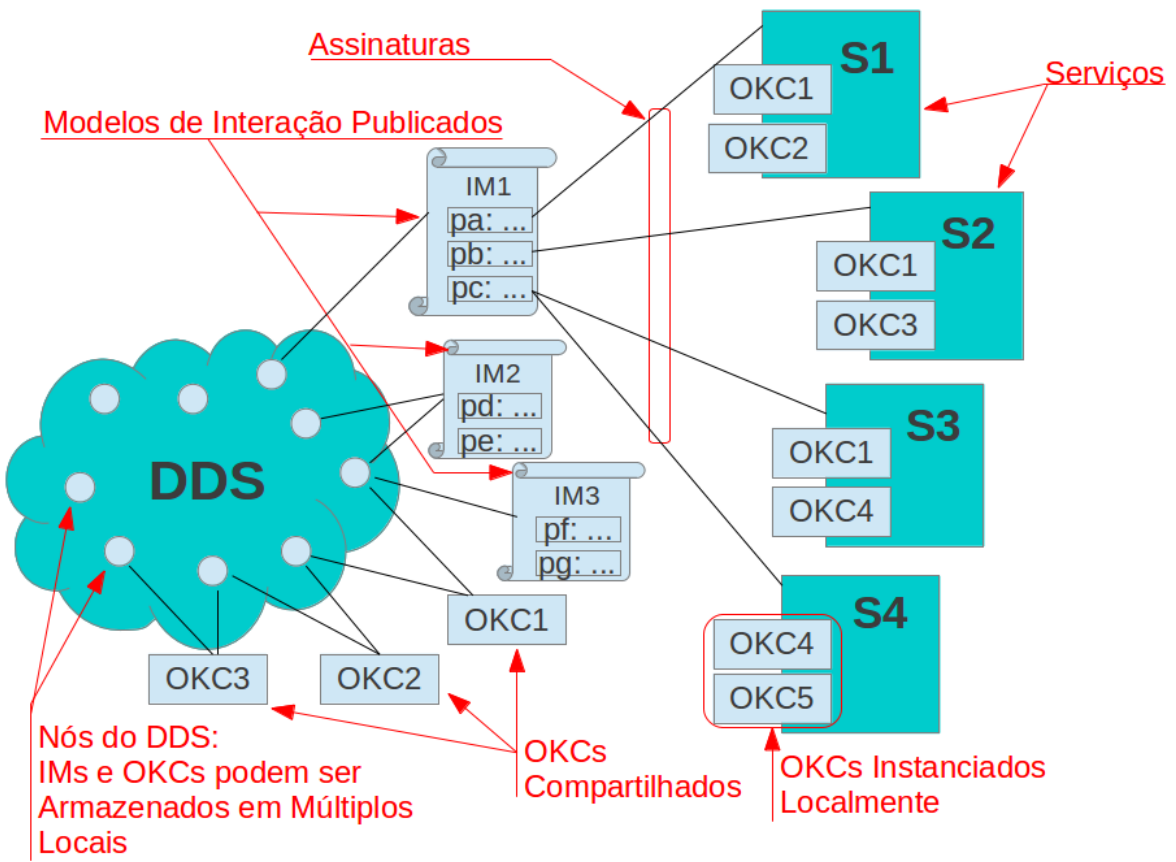

Figura 3.1: Arquitetura OK. Traduzida e baseada em [BBRW09]

uma implementação no OK. Os modelos interação IM1, IM2 e IM3 são publicados no DDS. Em IM1, papel pa é disponibilizado pelo serviço S1, o papel pb é disponibilizado por S2 e papel pc é disponibilizado por S3 e S4. Depois que todos os papéis são preenchidos, o DDS seleciona aleatoriamente um (ou mais) serviço(s) para atuar como coordenador para a interação e passa o modelo de interação juntamente com a lista de serviços envolvidos. O coordenador primeiramente pede que cada serviço selecione os serviços que desejam interagir, após isso, a divulgação dos modelos de interação pode começar.

\subsection{Lightweight Coordination Calculus (LCC)}

Os serviços web são partes de softwares que podem ser requisitados através de um protocolo padronizado. Eles podem ser combinados através de linguagens formalizadas que descrevem modelos de interação, como Web Services Business Process Execution Language (WS-BPEL), Web Services Choreography Description Language (WS-CDL) ou Lightweight Coordination Calculus (LCC), por exemplo.

LCC é uma linguagem para descrever interações em processos distribuídos através de processos de cálculo, foi projetada para ser simples e conduzir uma interação sem complexidade. O principal objetivo da LCC é interferir o mínimo possível com o projeto e operação de serviços individuais. Protocolos LCC são modulares no sentido de que eles podem ser independente dos serviços participantes nas interações que eles descrevem e são neutros em relação a implementação desses serviços. As cláusulas dentro de um protocolo de LCC também são modulares, então os papéis individuais dentro de uma interação são fáceis de identificar. Isso torna relativamente simples de projetar diferentes modelos de interação em LCC, dependendo das exigências do problema [Rob05]. IM, no OK, descrevem interações e são escritos em LCC.

Cada modelo de interação LCC é definido por um conjunto de cláusulas. Cada cláusula é uma definição independente de um papel, com a mensagem que passa a ser o único meio de transferência de informações entre os papéis. Passagem de mensagem é também o único meio de sincronização en- 
tre papéis. Para cada papel há uma sequência de passagem de mensagens estipuladas pela cláusula que atualmente está sendo usada, além de restrições associadas às mensagens de envio ou recebimento. Assim, os comportamentos mais básicos em LCC são de enviar ou receber de mensagens, onde o envio de uma mensagem pode ser condicionado à satisfação de uma restrição e o recebimento de uma mensagem implica no aceite das restrições pelo serviço [PDKS07].

Comportamentos são especificados usando os conectivos then, or e par para sequência, escolha e paralelização, respectivamente. Um conjunto de tais cláusulas comportamentais especifica o comportamento da mensagem [Rob05]. Listing 3.1 mostra um modelo de interação simples, escrito em LCC, para descobrir informações: um requisitante solicita informações e um informante responde. O exemplo utiliza o conectivo then para sequência de ações. Em LCC, as variáveis são identificadas por uma letra maiúscula, enquanto constantes começam com letra minúscula.

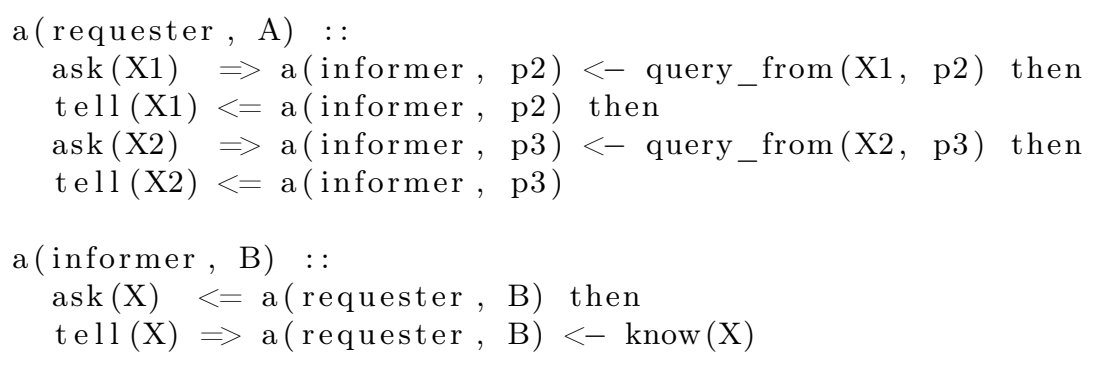

Listing 3.1: Exemplo de modelo de interação escrito em LCC. Fonte: [Rob05]

\subsubsection{Papéis}

IMs possuem dois ou mais papéis, cada papel descreve as ações necessárias para os serviços que vão participar da interação. Identificadores de papel tem a forma de (papel, ID) . Em Listing 3.1, o primeiro papel (a (requester, A) ) é requisitante (requester), e isso vai ser disponibilizado por um serviço com o ID A. A variável A será instanciada com a identificação dos serviços adequados. É possível fazer esta identificação através de uma constante, e assim o papel só é reproduzido por um serviço em particular identificado por essa constante, mas essa ação vai contra a ideia de reutilização IMs, por isso, geralmente, não é recomendada.

\subsubsection{Mensagens}

Mensagens são indicadas por setas duplas. À esquerda da seta dupla é a mensagem que está sendo passada e à direita é o papel para o qual será enviada ou recebida a mensagem. Dentro de um IM, a maioria das mensagens irão conter uma ou mais variáveis que não são determinadas pelo IM: por exemplo, em Listing 3.1, a variável X é passada. O valor dessa variável só é determinado durante tempo de execução: por isso, o IM é reutilizável em diferentes situações.

Qualquer mensagem que é enviada em um IM também deve ser recebida pelo papel adequado dentro desse IM, e, portanto, todas as mensagens são exibidas duas vezes, uma vez como uma mensagem enviada no papel do remetente e uma vez como uma mensagem recebida no papel do receptor. Quando existem apenas dois papéis, isto faz com que a passagem de mensagens por esses papéis seja completamente simétricas.

\subsubsection{Restrições}

Restrições são colocadas nas mensagens, que aparecem mais à direita em um IM e apontando para a mensagem, com uma seta simples, e tem duas funções:

1. Explicar como as variáveis nas mensagens deve ser instanciadas;

2. Limitar as circunstâncias em que uma mensagem pode ser enviada (só pode ser enviada se a restrição puder ser satisfeita pelo serviço que desempenhar o papel). 
Em Listing 3.1, por exemplo, o serviço que assume o papel de requisitante deve ser capaz de atender a restrição query_from (X1, p2). Qualquer serviço OK é capaz de passar qualquer mensagem, desde que as restrições necessárias estejam satisfeitas, portanto a capacidade de desempenhar um papel é equivalente à capacidade de satisfazer todas as restrições desse papel.

\subsection{OpenKnowledge Component (OKC)}

OKCs (OpenKnowledge Components) desempenham um papel em um IM. Muitos OKCs diferentes podem coexistir com a capacidade de desempenhar o mesmo papel no mesmo IM. Cabe ao usuário decidir qual deles atende às suas necessidades. OKCs são compostos das seguintes partes [PDKS07]:

- Referência IM - o identificador do IM que o OKC pode executar;

- Papel - o nome do papel que o OKC pode desempenhar;

- Annotation (opcional) - informações que descrevem a implementação do OKC;

- Código - os algoritmos que resolvem as restrições papel do IM referenciado;

- Facade - classe que estende a classe OKCFacadeImpl, funciona como um ponto de entrada para o código OKC.

OKCs contêm os métodos utilizados para resolver as restrições dos modelos de interação, suas classes expõem métodos que implementam algumas funcionalidades. Um OKC é um arquivo Java Archive (JAR) contendo uma classe facade que estende a classe OKCFacadeImpl no kernel e um arquivo xml, chamado okcinfo.xml descrevendo o componente. O arquivo JAR pode conter outras classes de apoio e recursos, mas a classe facade é o que deve expor todos os métodos que resolvem as restrições. Os papéis são implementados por OKCs. Listing 3.2 mostra um "esqueleto" de um OKC.

Um OKC é comparável a um serviço web: ele tem uma aplicação e uma maneira padronizada para descrever a funcionalidade. Como a funcionalidade implementada é transparente: pode ser uma invocação a um serviço web, uma chamada para um aplicativo legado ou podem ser autossuficientes e usar apenas o que está contido no JAR. OKCs pode ser publicado no DDS e baixado por qualquer serviço.

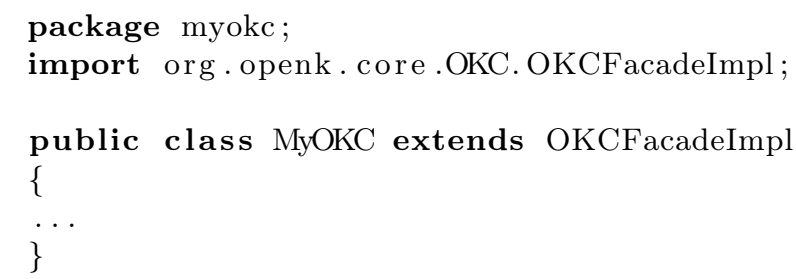

Listing 3.2: Esqueleto da Classe OKC. Fonte: [PDKSOク]

Um método deve:

- ser público;

- retornar um boolean;

- definir cada argumento como tipo Argument.

Mais de um OKC podem ser usados para resolver as restrições de um papel: o processo encontra os métodos correspondentes às restrições nos OKCs disponíveis no serviço e cria os adaptadores entre eles.

Por exemplo, uma cláusula de papel com o seguinte IM: 


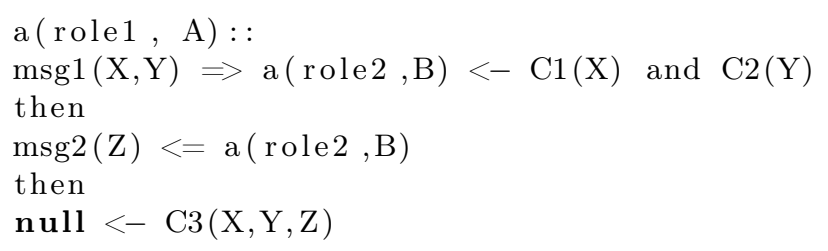

Listing 3.3: Exemplo de IM. Fonte: [PDKSO"]

Pode ter as restrições $\mathrm{C} 1, \mathrm{C} 2, \mathrm{C} 3$ combinadas com os métodos de $\mathrm{m} 1, \mathrm{~m} 2$ para $\mathrm{OKC} 1$ e m4 a partir de $\mathrm{OKC} 2$ :

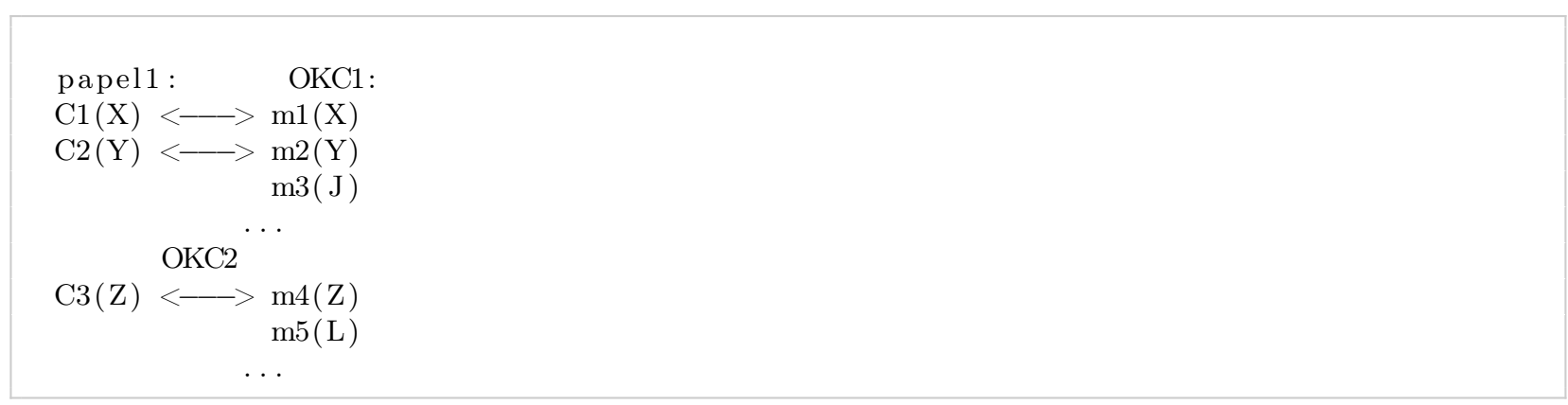

Listing 3.4: Exemplo de restrições. Fonte: [PDKSO'7]

\subsubsection{Repositório OKC}

OKCs são empacotados em um arquivo de modo que eles podem ser enviados pela rede facilmente. $\mathrm{O}$ arquivo contém o código compilado (opcionalmente, o código fonte também), e um arquivo XML que contém a referência IM, papel, annotation e Facade (ou seja, a descrição do OKC).

Cada serviço pode armazenar OKCs localmente no repositório OKC. Um serviço é capaz de acessar os OKCs armazenados nele e usá-los para interagir com outros serviços. OKCs descarregado a partir do OpenKnowledge e OKCs implementados podem ser armazenados no repositório. Cada serviço gerencia os OKCs que tem armazenados localmente e também pode atuar como um coordenador de uma interação entre OKCs. OKCs se comunicam com o coordenador através da camada de comunicação [PDKS07].

\subsubsection{Gerente de Controle}

O gerente de controle controla a execução dos serviços. O usuário pode interagir com os serviços por meio de uma interface do usuário. Seus eventos são tratados pelo gerenciador de controle que delega a solicitação para o módulos que podem satisfazê-los. O gerente de controle fornece controle de execução sobre os módulos do serviço. O gerente de controle serve como mediador, sempre que um módulo precisa usar a funcionalidade de outro módulo, ele pede ao gerente de controle, que delega para o módulo apropriado. O gerente de controle aciona os protocolos do sistema e acessa os diversos serviços oferecidos pela rede. Ele inicializa todos os módulos e serviços quando o serviço é inicializado e o fecha quando o serviço está parado [PDKS07].

\subsubsection{Instância Repositório}

Quando o usuário começa a interagir através de um de seus OKCs, uma nova instância do OKC é criada que vai desempenhar o seu papel no IM. Uma nova instância precisa ser criada, uma vez que o OKC pode tomar parte em mais de uma interação. O serviço precisa gerenciar todos esses casos, e isso é feito através da instância de repositório [PDKS07]. 


\subsubsection{Coordenadores e Intérpretes}

Serviços podem inscrever-se para desempenhar o papel de coordenador. O coordenador é um serviço que irá executar um IM localmente, interpretando-o, armazenando o estado e administrando a troca de todas as mensagens. É incapaz de fornecer uma funcionalidade específica que o IM requer (ou seja, resolver restrições), o coordenador entrará em contato com os OKCs executando os papéis de mensagens instantâneas para fornecer essa funcionalidade. Quando o intérprete se depara com uma restrição, o coordenador a intercepta e a entrega para um serviço que tenha se inscrito para desempenhar o papel que fornece a funcionalidade [PDKS07].

\subsubsection{Demais Elementos OK}

Além dos elementos citados, existe um conjunto de elementos que não são essenciais para todos os serviços, mas são essenciais para o sistema como um todo. Portanto, um subconjunto de serviços OK precisa executá-los. Alguns serviços, que atuam como coordenadores, precisam interpretar os IMs e coordenar a comunicação entre OKCs. Além disso, algumas tarefas são prestados aos serviços para ajudar no processo de interação, como o DDS, já citado, que armazena IMs, OKCs, e suas assinaturas. Há também o Confiança e Serviço de Reputação (TRS - Trust and Reputation Service) é usado para coletar informações sobre outros serviços, a fim de orientar o usuário na escolha de parceiros de interação e o Serviço de Mapeamento (MS - Mapping Service) é utilizado pelos serviços na interação com o outros OKCs, ele ajuda a entender quais são os outros OKCs que o serviço está interagindo [PDKS07].

\subsection{Seleção de Serviços no OK}

A estrutura o OK possibilita a criação de coreografias de forma rápida, pois sua estrutura possibilita abstrair detalhes de implementação como coordenação de serviços, instância de repositório, troca de mensagens, publicação de IM, etc. A estrutura do OK permite também que se utilize seleção de serviços através da classe InteractionTask utilizando o construtor set SelectionStrategy e a estratégia de seleção é definida quando o serviço se inscreve para o papel.

No Kernel OK há a implementação do algoritmo GEA 3.4.1, que implementa a classe PeerSelectionStrategy. A partir dele, pôde-se obter o "esqueleto" para a implementação da nossa proposta, como acesso a lista de participantes por papel, por exemplo.

\subsubsection{Good enough answer algorithms(GEA)}

Good enough answer algorithm (GEA) [GSM+ ${ }^{+}$]] é um algoritmo que determina se uma potencial interação entre serviços é boa o suficiente para ser realizada. Isso envolve tanto descobrir um modelo de interação adequado, quanto determinar se outros serviços podem desempenhar seus papéis a um nível que é considerado bom o suficiente para a interação. Assim, serviços que são julgados inadequados serão rejeitados como potenciais parceiros de interação. O GEA está implementado no OK e pode ser usado para selecionar serviços desde que se tenha a pontuação correspondente de cada serviço e a pontuação de confiança. Para selecionar um serviço, primeiro o GEA remove todos os serviços com uma pontuação abaixo de um limiar definido e, em seguida, para os serviços restantes, calcula suas pontuações de confiança com base em seu comportamento histórico (no intervalo [0 - 1]). O melhor serviço é aquele para o qual a combinação de confiança e pontuação correspondente é maior, calculado de acordo com a Equação 3.1 .

$$
G i=t_{i} \cdot V+m_{i} \cdot(1-V)
$$

onde:

t_i é a pontuação de confiança para serviço_i;

$m \_i$ é a pontuação correspondente do serviço_i e 
$V$ é um parâmetro.

A Equação (3.1) gera uma pontuação única no intervalo [0 - 1] [GPB07]. A Figura 3.2 ilustra o funcionamento do algoritmo, em que dado um conjunto de serviços o GEA seleciona os que possuem melhor pontuação para um determinado papel combinando as pontuações (representadas por $M i$ e $T i$ ) resultando na pontuação $G i$ para o i-ésimo serviço considerado. Por fim, Interpretação escolhe o melhor serviço com base nas pontuações. A Figura 3.3 mostra um diagrama de classe para a estratégia de seleção de serviços do GEA.

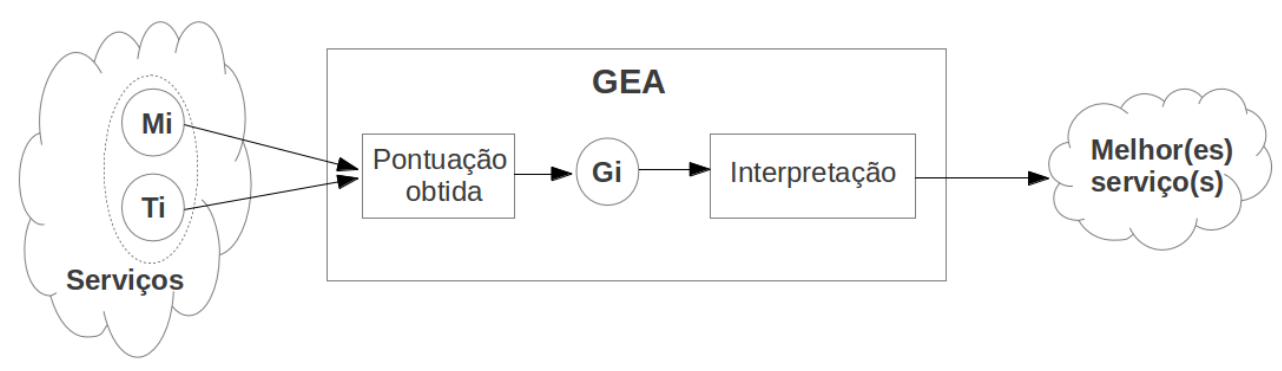

Figura 3.2: Arquitetura GEA. Traduzida e baseada em [GPBOr]

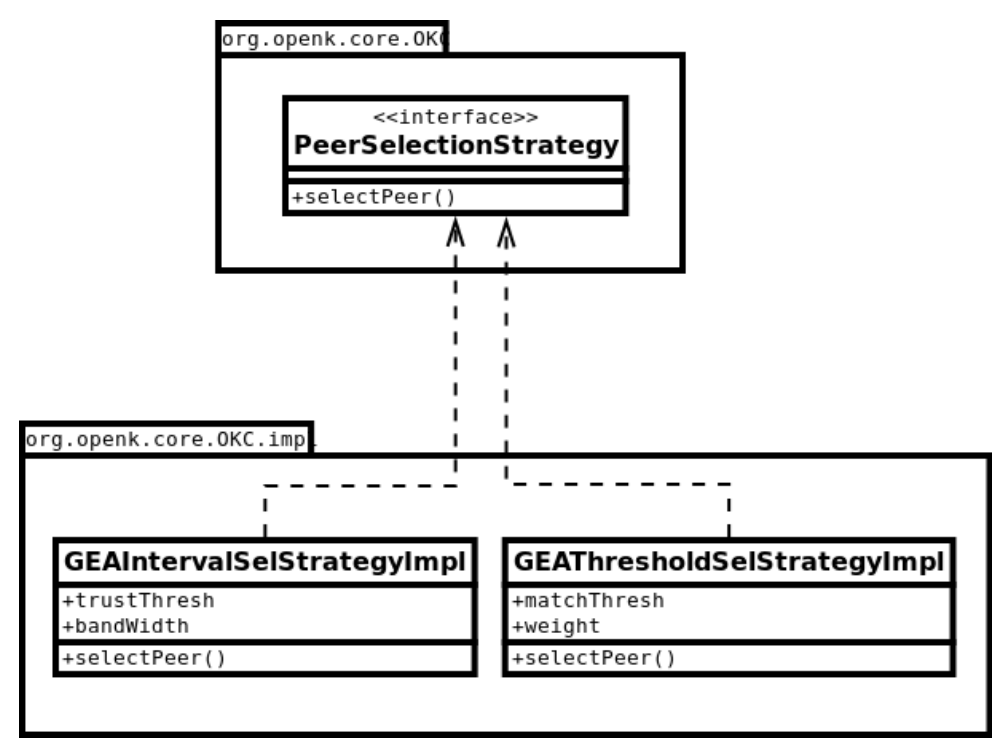

Figura 3.3: Diagrama de Classe GEA. Traduzida e baseada em [GPB07]

\subsubsection{Seleção FIFO}

Caso nenhum algoritmo de seleção seja instanciado no OK, por padrão as escolhas de serviços que desempenham determinado papel são feita de forma que o primeiro que entra na lista de serviços é o primeiro a ser selecionado, ou seja, uma estratégia FIFO (First In, First Out), que acontece da seguinte forma:

Quando um papel é solicitado no modelo de interação, o serviço requisitante verifica na lista de inscritos quais serviços o desempenham, A partir disso, o primeiro serviço que se inscreveu para esse papel (e está armazenado na lista) é selecionado.

Caso haja mais de um serviço inscrito em um determinado papel, essa estratégia acaba sendo inviável, pois as escolhas acontecem sem nenhum critério preestabelecido. Por essa razão, a estratégia foi escolhida como ponto de comparação para nossa proposta, pois assim será capaz de verificar como ocorrem as escolhas de serviços com e sem critérios de seleção preestabelecidos. 


\section{Capítulo 4}

\section{Trabalhos relacionados}

Este capítulo trata do referencial teórico que foi abordado nesta pesquisa procurando fundamentar os estudos relativos à seleção de serviços web e à utilização de framework OpenKnowledge para implementação de coreografias.

Segundo [Lea04] seleção de serviços web pode ser conduzida de diferentes formas de acordo com as preferências ou necessidades do usuário. Assim, pode haver seleção de serviços web orientada completamente por preço (independentemente do tempo que demora a execução), por critérios como taxa de penalização (para a rescisão antecipada de contrato, por exemplo), outras por capacidade de executar os serviços corretamente, considerando a reputação do serviço (que podem ser vistos como mais importante do que preço e tempo) e outras que podem ser conduzidas completamente pelo tempo (em aplicações sensíveis a atraso, por exemplo).

A execução por preço considera quanto o solicitante de serviço deve pagar para o prestador de serviços para usar um serviço web, tais como a verificação de um crédito ou a quantidade de dinheiro que o solicitante do serviço tem de pagar ao prestador de serviços. Prestadores de serviços web ou anunciam diretamente o preço de execução de seus serviços ou fornecem os meios para os potenciais solicitantes possam buscar essa informação.

A reputação de um serviço é uma medida de sua confiabilidade. Depende, principalmente, de experiências de utilização do serviço pelo usuário final. Usuários finais diferentes podem ter opiniões diferentes sobre o mesmo serviço. O valor da reputação é definido como a classificação média atribuída ao serviço por usuários finais. Normalmente, os usuários finais recebem um intervalo de classificação de serviços web. Por exemplo, na Amazon.com, o intervalo é de [0 - 5].

A execução por duração mede o atraso previsto entre o momento em que um pedido é enviado e o momento em que o serviço é prestado. A duração de execução é a soma do tempo de processamento e o tempo de transmissão.

Liu et al. (2004) [Lea04] utilizam o termo QoS de serviços web e afirma que pode-se considerar critérios de seleção como: preço, taxa de penalização, confiabilidade, disponibilidade e tempo de execução. Porém, utiliza apenas preço, duração da execução e reputação como critérios para selecionar serviços e propõe um modelo onde se obtém valores de QoS tanto com base em monitoração da execução por parte dos utilizadores, quanto através de feedback do usuário, dependendo das características de cada critério de QoS.

Zeng et al. (2003) [ZBD $\left.{ }^{+} 03\right]$ consideram a seleção de serviços segundo critérios relacionados a preço, tempo de execução e confiabilidade. Os autores defendem que a seleção de serviços deve ser realizada em tempo de execução da composição, ao invés de em tempo de projeto. Consideram as restrições globais e as preferências definidas pelo usuário, como por exemplo: as restrições de valor a ser pago por um serviço. Assim, o trabalho propõe uma abordagem de planejamento global para selecionar serviços durante a execução de uma composição. A seleção de serviços é formulada como um problema de otimização que pode ser resolvida usando métodos para solução de problemas de programação linear. O trabalho conclui que há vantagens na utilização da abordagem de planejamento global com relação a abordagens em que os componentes de serviços são selecionados individualmente para cada tarefa em uma composição. O principal entrave dessas abordagens se 
dá ao fato de precisar do usuário para obtenção de critérios de seleção. Dessa forma, assim como no algoritmo GEA, torna as abordagens pouco dinâmicas, não sendo possível realizar a seleção independente das escolhas do usuário.

He et al. (2012) [HHY ${ }^{+}$12] definem Sistemas Baseados em Serviços (SBSs) como sistemas que são construídos por meio de composição dinâmica de serviços e afirma que devem ser monitorados para garantir um melhor tempo de resposta da aplicação. O trabalho considera a priorização da monitoração do caminho crítico de um SBS como maior custo-benefício, isto é, o caminho de execução da composição de serviço com o tempo máximo de execução, uma vez que determina o tempo de resposta do SBS. Em ambientes operacionais voláteis, o caminho crítico de um SBS é probabilístico. Como tal, é importante para estimar os pontos críticos dos caminhos de execução e os serviços que o compõe, ou seja, a probabilidade de eles serem críticos. O trabalho propõe uma abordagem para a identificação de Caminho Crítico Probabilístico para Sistemas Baseados em Serviço (PCP-SBS). PCP-SBS leva em conta a natureza probabilística do caminho crítico e calcula os problemas do caminho no contexto da composição de serviços. PCP-SBS foi avaliado experimentalmente usando SBSs com base em um conjunto de dados de serviços web no mundo real. O critério considerado como importante para seleção de serviços no trabalho é o tempo de resposta. Uma gestão eficaz do tempo de resposta tende a melhorar gestão de outras dimensões de QoS, pois muitos aplicativos exibem trade-offs entre seus tempos de resposta e suas outras dimensões de QoS [MSHR10]. A aplicação de codificação de vídeo, por exemplo, muitas vezes pode produzir vídeo de qualidade superior se o tempo de chegada de cada quadro foi pequeno. Além disso, a administração de outras dimensões de QoS é rigidamente acoplada com a gestão do tempo de resposta. Segundo os autores, durante a execução de um SBS, muitas vezes é necessário que haja adaptações ou ajustes em tempo de execução para evitar o comprometimento da qualidade. A adaptação em si consome tempo, e, como resultado, contribui para retardar a execução do SBS. Problemas tratados em tempo de execução que ocorrem no caminho crítico da composição de serviços, ou seja, o caminho de execução com o tempo máximo de execução, irá causar atrasos que afetam diretamente o tempo de resposta do SBS. Assim, a detecção oportuna e previsão problemas em relação ao tempo de execução, especialmente aqueles que ocorrem em um caminho crítico, são significativas para uma gestão eficaz do tempo de resposta em SBSs. Contudo, o trabalho não analisa o causador do problema afeta a composição e causando atrasos no tempo de execução, e considera apenas como caminho crítico aquele que se obteve maior tempo de resposta, não analisando critérios que possam afetar o meio de transmissão e também a execução do serviço.

Ramacher e Mönch (2014) [RM14] consideram que composições de serviços são utilizadas para implementar processos de negócios em diferentes domínios de aplicação. O trabalho considera que há múltiplos critérios de escolha de serviços, que muitas vezes podem ser conflitantes e incertos. Sendo assim, é apresentada uma abordagem de seleção serviço com heurística de multicritérios que se destina a determinar a fronteira de Pareto para seleções de serviços alternativos com objetivos de melhorar o tempo de execução. Levando-se em conta a incerteza dos tempos de resposta, as seleções de serviços obtidas são robustas em relação ao tempo de execução restrito. A solução proposta baseia-se na Non-dominated Sorting Genetic Algorithm (NSGA)-II que se estende por heurísticas que exploram características específicas do problema da seleção de serviços QoS-aware. Os experimentos mostraram que a abordagem é adequada para uma seleção serviço em tempo de execução porque soluções Pareto ideais são obtidas em poucos minutos. Além disso, foi mostrado que vale a pena antecipar a incerteza quando as decisões de seleção de serviço QoS-aware são feitas. Esta característica da abordagem é importante do ponto de vista gerencial. Além disso, os autores afirmam que a combinação de uma maior disponibilidade de dados e avanços em algoritmos pode levar a novos tipos de sistemas de apoio à tomada de decisão. O trabalho não considerou falhas e indisponibilidade de serviços. A aplicabilidade da abordagem de solução foi demonstrada apenas por simulação, descartando a possibilidade de verificar a viabilidade da proposta em um cenário real onde há influência das características do meio e de agentes externos. Nenhum dos trabalhos citados acima descrevem o comportamento de suas propostas diante cenários distribuídos.

No que diz respeito à seleção de serviços em coreografias, os critérios utilizados, observados na 
literatura, são: conformidade, objetivo e confiabilidade.

Para Baldoni et al. (2008) $\left[\mathrm{BBM}^{+} 08\right]$ o papel que um serviço web deve desempenhar em uma coreografia implica na verificação de dois critérios: conformidade (ou correspondência) e objetivo. Ou seja, a conformidade do serviço com a especificação de um determinado papel, e se o serviço atende ao objetivo que se propõe. Conformidade garante a interoperabilidade com os atores dos outros papéis ao garantir que a troca de mensagens irá produzir conversas corretas e aceitas. Já o objetivo que causou a busca de um serviço é uma condição que deve ser mantida após toda interação ocorrer. O esquema de correspondência, que é aplicado para descobrir serviços, não só deve focar em propriedades das operações locais, mas também deve considerar o esquema global de execução que é dado pela coreografia. Dessa forma, o trabalho foca apenas na relação entre regras de correspondência e na realização de um objetivo para selecionar serviços em uma coreografia.

Hwang e Lee (2013) [HL13] propõem um modelo em que cada serviço web participante está associado a um processo abstrato que é capaz de realizar de forma dinâmica a seleção de serviços. Os autores propõem um método para cada serviço web selecionar e requisitar outros serviços de forma dinâmica, com base em informações sobre os demais serviços. Isto aumenta a probabilidade de completar toda a coreografia em um ambiente sujeito a falhas. Dessa forma, o trabalho fornece as seguintes contribuições para o problema de seleção de serviços web em um ambiente coreografado: (1) cada serviço web não tem informações sobre todos os serviços da coreografia. Em vez disso, um serviço somente oferece um resumo do comportamento de si mesmo e de outros serviços parceiros para um serviço web central, que respeite a confidencialidade dos parceiros de negócios; (2) na proposta do arcabouço de seleção de serviços web para um modelo de coreografia, cada serviço participante faz sua seleção com base em informações lançadas pelos serviços web do parceiro; (3) foi comparado o desempenho de vários algoritmos de seleção de serviços web que usam diferentes informações para decidir sobre o melhor serviço para realizar um papel. Apesar da característica distribuída necessitar do conhecimento de todos os participantes em relação ao meio de transmissão no momento de realizar a seleção para evitar possíveis gargalhos, nenhum dos trabalhos que abordam seleção de serviços em coreografias consideram as características do meio para realizar a seleção.

Com relação a implementação de coreografias no OK, Barker et al. (2009) [BBRW09] demonstram as vantagens na utilização de coreografias no framework OpenKnowledge juntamente com LCC (linguagem que descreve coreografias utilizada pelo framework). Porém, não faz nenhuma alteração significativa no framework. O trabalho apresenta inicialmente a comparação entre coreografia e orquestração no que diz respeito ao fluxo total de dados transferidos pela rede utilizando padrões de comunicação com relacionamentos $N: 1,1: N$ e $1: 1$, extraídos do grafo de comunicação da aplicação Montage. Foram propostas as equações para efetuar o cálculo do fluxo total de dados utilizando estes padrões para orquestração e coreografia, respectivamente e os autores as utilizaram para concluir que a coreografia é uma ótima solução comparada a orquestração, quando a composição apresenta um grande fluxo de dados.

Besana et al. (2009) $\left[\mathrm{BPB}^{+} 09\right]$ propõem uma abordagem distribuída (coreografada) utilizando openKnowledge como base. A coreografia descreve as interações de atores na definição de diretrizes médicas, uma tarefa que, segundo os autores, tem alta complexidade e heterogeneidade de componentes pois os atores codificam diferentes aspectos de um procedimento médico, e especificam diferentes níveis de abstração destes procedimentos. O trabalho se concentra na aplicação do OK para a coordenação das diretrizes médicas, utilizando como estudo de caso os procedimentos de avaliação, chamados de avaliação tripla, analisando um paciente com suspeita de câncer de mama. Uma arquitetura baseada em coreografia pode ajudar desenvolvedores a pensar sobre aplicações distribuídas por uma perspectiva diferente, que tenha uma melhor escalabilidade com o incremento do número de atores que interagem. Na abordagem proposta no trabalho, a coreografia é publicada em um repositório compartilhado de forma semelhante à publicação de uma diretriz médica por um comitê. Participantes compartilham a coreografia apropriada quando eles precisam realizar uma atividade que requer a atividade coordenada de outros atores. As coreografias são combinadas com a capacidade dos participantes: os participantes selecionam a coreografia que melhor se adéqua a eles e anunciam a sua intenção de desempenhar um papel nelas. Um mesmo papel podem estar 
disponíveis a partir de muitos serviços, e o processo de pesquisa e descoberta pode ser complexo, especialmente se ele precisa ser executado em tempo real. O framework openKnowledge auxiliou nesse aspecto do trabalho, pois lida com estas questões. O trabalho conclui que sistemas para diretrizes médicas, tipicamente projetados para operar de forma centralizada, podem ser reconstruídos de modo descentralizado. Foi observado ainda que o kernel genérico do openKnowledge é suficiente para a implementação de tais sistemas. No entanto, o trabalho não realizou nenhuma modificação significativa no OK, principalmente em relação a seleção dos serviços, foi utilizada a seleção padrão do OK.

Não há na literatura trabalhos que focam na utilização de OK e na modificação de sua abordagem de seleção, como mostra a Tabela 4.1. Em relação à seleção de serviços web, nenhum dos trabalhos considera o estado da rede como critério de seleção, como mostra Tabela 4.2, porém deixam claro que é importante para o desempenho e um bom tempo de execução a escolha do melhor caminho entre os nós $\left[\mathrm{HHY}^{+} 12\right]$. O critério "Capacidade de executar serviço corretamente"corresponde a critérios como: confiabilidade, grau de confiança, reputação, comportamento, conformidade e objetivo. O Seletor está destacado como o único capaz de realizar seleção considerando todos os critérios, pois pode ser configurável para realizar a seleção de serviços utilizando qualquer parâmetro, como será mostrado no Capítulo 5.

\begin{tabular}{|l|c|c|c|}
\hline \multirow{2}{*}{ Trabalho Relacionado } & \multirow{2}{*}{ OK } & \multicolumn{2}{|c|}{ Seleção de Serviços } \\
\cline { 3 - 4 } & & Coreografia & Outros \\
\hline Barker et al. (2009) & $\mathrm{x}$ & & \\
\hline Besana et al. (2009) & $\mathrm{x}$ & & \\
\hline Zeng et al. (2003) & & & $\mathrm{x}$ \\
\hline Liu et al. (2004) & & & $\mathrm{x}$ \\
\hline He et al. (2012) & & & $\mathrm{x}$ \\
\hline Ramacher e Mönch (2014) & & & $\mathrm{x}$ \\
\hline Baldoni et al. (2008) & & $\mathrm{x}$ & \\
\hline Hwang e Lee (2013) & & $\mathrm{x}$ & \\
\hline
\end{tabular}

Tabela 4.1: Trabalhos Relacionados

\begin{tabular}{|l|l|l|l|l|l|l|l|}
\hline $\begin{array}{l}\text { Critérios de } \\
\text { Seleção }\end{array}$ & $\begin{array}{l}\text { Zeng et al. } \\
(2003)\end{array}$ & $\begin{array}{l}\text { Liu et al. } \\
(2004)\end{array}$ & $\begin{array}{l}\text { He et al. } \\
(2014)\end{array}$ & $\begin{array}{l}\text { Ramacher } \\
\text { e Mönch } \\
(2014)\end{array}$ & $\begin{array}{l}\text { Baldoni et } \\
\text { al. (2008) }\end{array}$ & $\begin{array}{l}\text { Hwang e Lee } \\
(2013)\end{array}$ & Seletor \\
\hline Preço & $\mathrm{x}$ & $\mathrm{x}$ & & & & & $\mathrm{x}$ \\
\hline $\begin{array}{l}\text { Capacidade } \\
\text { de executar } \\
\text { os serviços } \\
\text { corretamente }\end{array}$ & $\mathrm{x}$ & $\mathrm{x}$ & & & $\mathrm{x}$ & $\mathrm{x}$ & \\
\hline $\begin{array}{l}\text { Tempo de } \\
\text { execução }\end{array}$ & $\mathrm{x}$ & $\mathrm{x}$ & $\mathrm{x}$ & & & & $\mathrm{x}$ \\
\hline Rede & & & $\mathrm{x}$ & & & & \\
\hline Processamento & & & $\mathrm{x}$ & & & & $\mathrm{x}$ \\
\hline Multicritérios & & & & & & & \\
\hline
\end{tabular}

Tabela 4.2: Critérios de Seleção 


\section{Capítulo 5}

\section{Seletor de serviços}

No contexto de coreografias, onde cada serviço é independente, a demora em relação a resposta de um serviço pode causar atrasos no sistema como um todo, afetando o desempenho da composição. Coreografias, apesar de um esquema descentralizado, podem também, por exemplo, causar gargalos quando vários serviços solicitam um mesmo serviço e/ou a coreografia necessita de um grande fluxo de dados e a rede não é capaz de atender a demanda esperada. Esse problema pode ser contornado ou melhorado se houver uma análise da rede previamente a realização da escolha do serviço. Além disso, considerar outros parâmetros antes de selecionar um serviço pode auxiliar em melhores escolhas. Por exemplo, uma grande sobrecarga de processamento também pode causar atrasos na execução de um serviço e afetar o tempo de execução de coreografias.

O mecanismo de seleção de serviços em coreografias proposto considera, primeiramente, o estado da rede. Em seguida, foi considerado que o desempenho de coreografias pode ser prejudicado não apenas pelo estado da rede (congestionamento), mas também por outras vertentes, como a capacidade de processamento da máquina (sobrecarga) que disponibiliza um determinado serviço.

Foram utilizados dois métodos para realizar seleção. O primeiro foi o método de comparação de valores de parâmetros de rede para selecionar o participante da coreografia que possui menor valor. Em seguida, foi inserido um algoritmo baseado em pontuação de serviços para realizar a seleção analisando parâmetros de rede e de processamento. O objetivo do segundo método é propor uma abordagem onde é possível utilizar diversos parâmetros conjuntamente para realização de seleção de serviços. Neste trabalho foi utilizado além de parâmetros de rede, também o parâmetro de utilização de CPU. No entanto, parâmetro como consumo de memória, por exemplo, poderia ser inserido sem grande dificuldade.

\subsubsection{Algoritmos de comparação}

O método de comparação utilizado primeiramente analisa os valores de atrasos ou perda para selecionar o participante da coreografia que possui menor valor, diante de um desses critérios. O mecanismo utiliza uma ferramenta externa e obtêm esses valores de todos os serviços existentes em paralelo a execução da coreografia. A forma como as medições são feitas não altera o funcionamento da proposta, por ser uma ferramenta externa. O Algoritmo 1 (Selector Atraso ou Perda) mostra como - após obtidos os valores de atraso ou perda - a escolha do serviço é realizada. O algoritmo é simples e busca o valor mínimo dentre uma lista de valores.

Com o objetivo de utilizar conjuntamente dois parâmetros para realizar a seleção de serviços foi desenvolvido outro algoritmo baseado no Algoritmo 1. O Algoritmo 2 (Selector Atraso e Perda) mostra como - após obtidos os valores de atraso e perda - a escolha do serviço é realizada, combinando os dois parâmetros. 

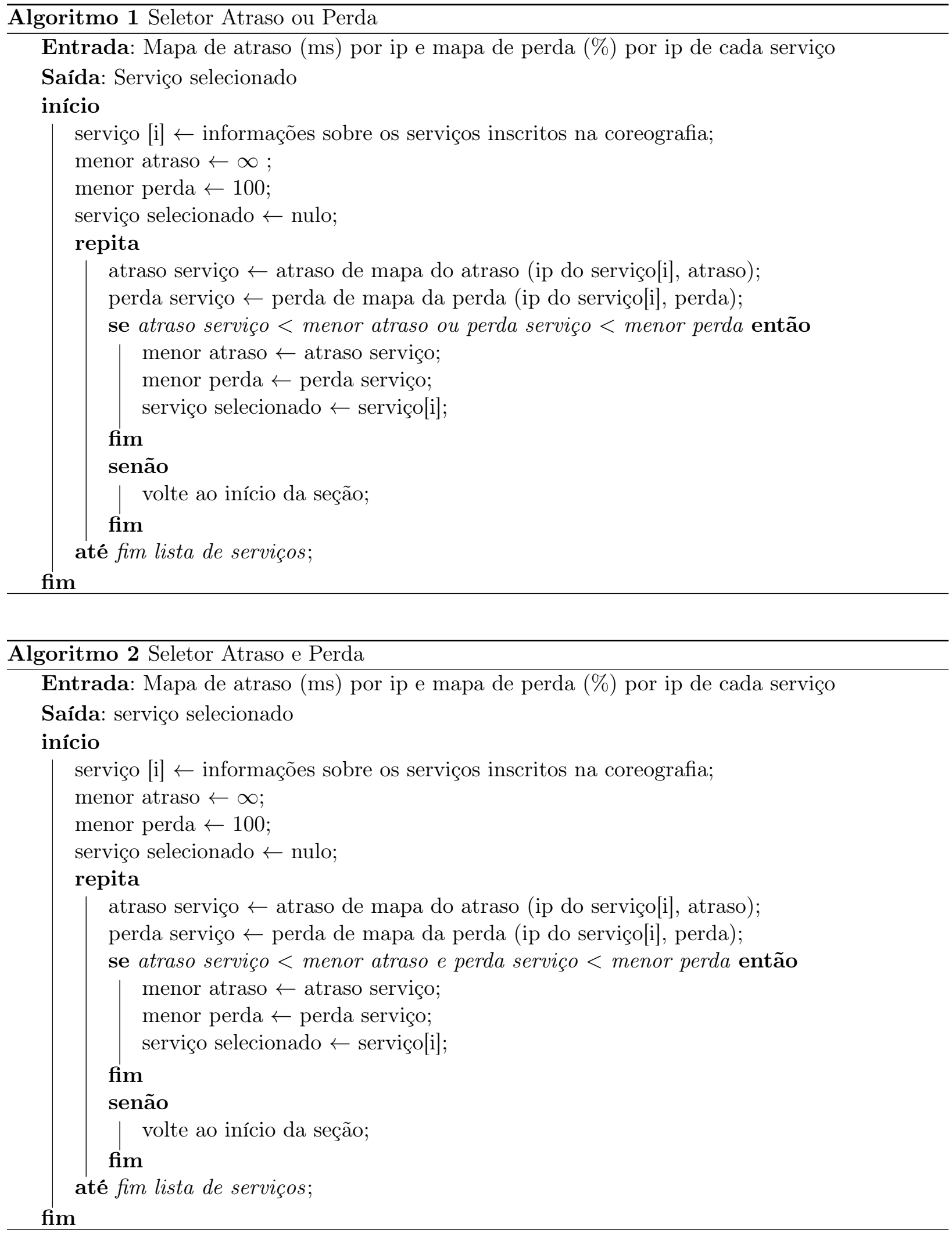

A principal diferença entre os dois algoritmos apresentados é utilização da condicional para realizar a escolha do serviço. O Algoritmo 1 utiliza a condicional "ou" e é capaz de utilizar apenas um parâmetro para realizar a seleção de serviço. O Algoritmo 2 utiliza a condicional "e" para realizar a escolha, sendo possível utilizar conjuntamente dois parâmetros para realizar a seleção, ele surgiu a partir dessa pequena modificação no primeiro algoritmo apenas para representar a possibilidade de utilização de mais de um parâmetro de seleção. No entanto, tal configuração, apesar de mais simples, não é viável para utilização proposta, pois torna o algoritmo complexo (caso seja inserido 
muitos parâmetros) e sua execução se torna lenta.

\subsubsection{Algoritmo de pontuação}

A partir da problemática apresentada nos algoritmos propostos anteriormente, desenvolveuse um terceiro algoritmo baseado na técnica de pontuação para seleção de serviços presente no algoritmo GEA com o objetivo de utilizar mais de um parâmetro de seleção.

Seu funcionamento se dá através de pontuação de cada parâmetro utilizado, essa pontuação é obtida através de uma tabela com pontuações preestabelecidas, de acordo com o valor obtido do parâmetro. Para este trabalho, foram criadas seis categorias para pontuação a partir das observações aos experimentos realizados com os algoritmos apresentados na seção 5.0.3, onde em cada categoria são dados pontos conforme os valores de atraso e perda. Como complemento, foi inserido também outro parâmetro, que é o de utilização de CPU, para realizar a seleção. Os valores visualizados na tabela para esse novo parâmetro foram obtidos através de execuções preliminares utilizando esse parâmetro. O algoritmo funciona da seguinte forma: quando maior valor do parâmetro, menor a pontuação agregada ao serviço. O serviço escolhido é aquele com maior pontuação depois dessa classificação.

Os intervalos de pontuação a partir dos valores obtidos em cada parâmetro foram estipulados a partir dos experimentos realizados previamente com os algoritmos de comparação (capitulo 6). Tais experimentos mostraram que os melhores serviços escolhidos apresentavam atraso de no máximo $1 \mathrm{~ms}$. Dessa forma, a categoria 1 agrega 1,0 ao serviço que apresentar valores de atraso menores que $1 \mathrm{~ms}$. A categoria 1 prevê a mesma pontuação para os serviços que apresentem perda menor que $1 \%$ e utilize menos de $2 \%$ de CPU. O valor escolhido de utilização de CPU foi devido medições com computadores sem nenhuma aplicação - além do serviço - rodando e mostraram valores de utilização de CPU variando entre 1 e $2 \%$. A partir desses valores foram criados faixas de valores para cada parâmetro em cada uma das categoria, como mostra a Tabela 5.1.

\begin{tabular}{|c|c|c|c|c|}
\hline Categoria & Pontuação & Atraso (ms) & Perda (\%) & CPU (\%) \\
\hline \hline 1 & 1,0 & $<1$ & $<1$ & $<2$ \\
\hline 2 & 0,5 & {$[1-2]$} & {$[1-5]$} & {$[2-10]$} \\
\hline 3 & 0,4 & {$[2-3]$} & {$[5-10]$} & {$[10-20]$} \\
\hline 4 & 0,3 & {$[3-4]$} & {$[10-15]$} & {$[20-30]$} \\
\hline 5 & 0,2 & {$[4-8]$} & {$[15-25]$} & {$[30-60]$} \\
\hline 6 & 0,1 & $>8$ & $>25$ & $>60$ \\
\hline
\end{tabular}

Tabela 5.1: Categorias Pontuação

Nos experimentos preliminares, observou-se que serviços que apresentavam maior tempo de execução apresentaram valores de atraso maiores que $8 \mathrm{~ms}$ e taxas de perda a partir de $25 \%$. Por essa razão, as menores pontuações dos parâmetros atraso e perda foram estabelecidas para serviços que obtiveram valores de atraso e taxas de perda a partir de $8 \mathrm{~ms}$ e $25 \%$, respectivamente. A variação dos valores dos parâmetros em cada categoria foi determinada de acordo com a especificidade de cada parâmetro e com o objetivo que se pretende atingir, ou seja, para o exemplo utilizado priorizava-se serviços que tinham taxas de perda e atraso melhores que porcentagem de utilização de CPU, dessa forma, a variação para pontuação de utilização de CPU foi maior do que a de perda, por exemplo. Todos esses valores são configuráveis de acordo com a necessidade e especificidade da composição.

O algoritmo Selector calcula a pontuação de cada serviço realizando a soma das pontuações obtidas. O pontuação de cada serviço é atribuída de acordo com os parâmetros utilizados. No exemplo, foi utilizado valores referentes a atraso, perda e utilização de CPU, e o Selector seleciona o serviço com maior pontuação, conforme mostra o Algoritmo 3. 


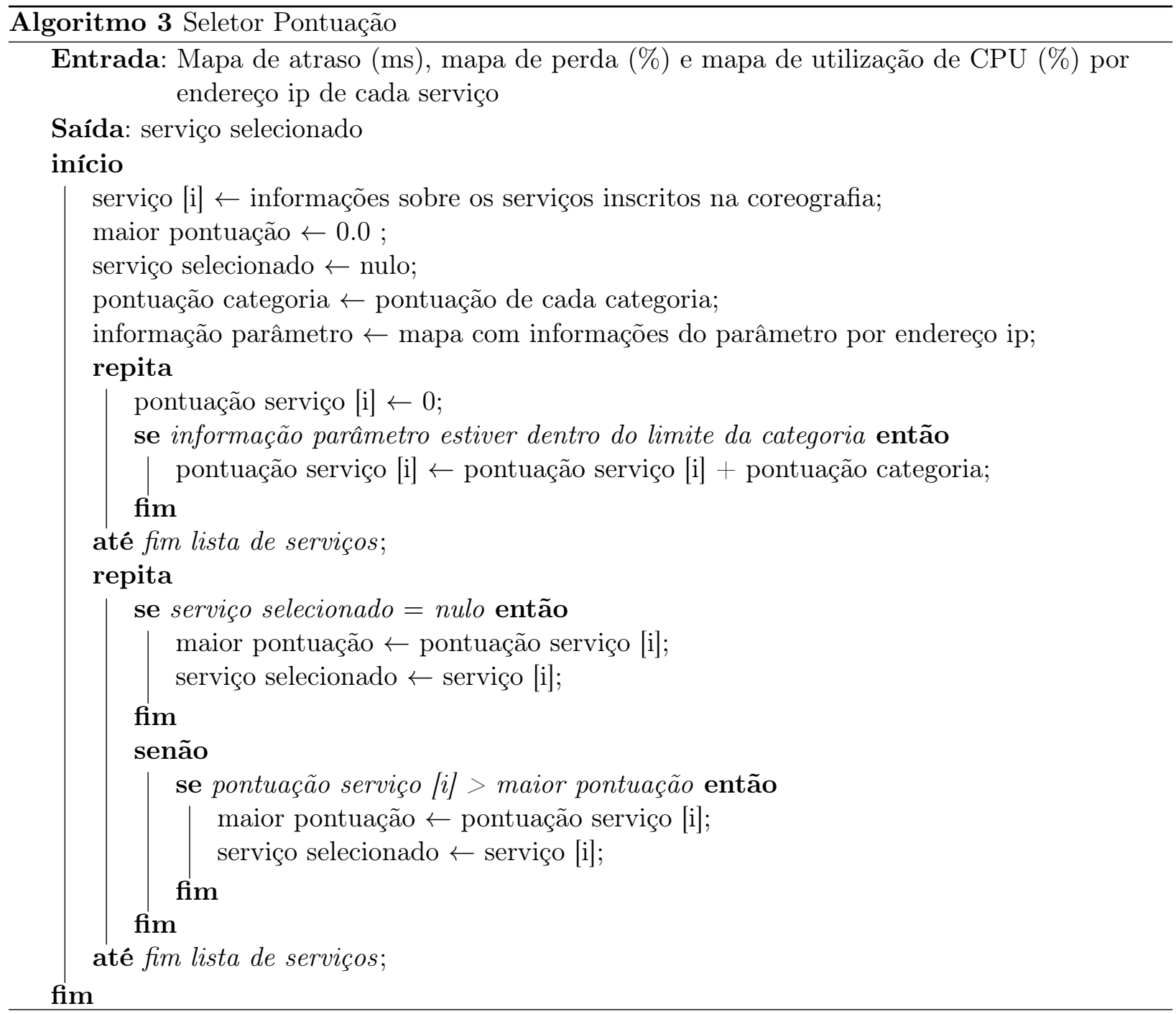

\subsubsection{Implementação no OK}

Foram implementadas duas classes para realizar o processo de seleção. A primeira classe, chamada Selector, recebe informações oriundas da segunda classe chamada SelectorUtil que contêm associações de atrasos, perda e utilização de CPU por serviço, essa classe é responsável por armazenar informações de cada nó que disponibiliza os serviços que desempenham determinado papel. Essas associações são criadas a partir de medições de atraso, perda e utilização de CPU através de ferramentas externas ao OK. A Figura 5.1 ilustra a generalização da implementação, que pode suportar qualquer parâmetro de seleção, desde seja fornecida informações de ferramentas externas. Neste trabalho utilizou-se um algoritmo que utiliza a ferramenta Ping para obter informações sobre a rede e um script que obtém informações de utilização de CPU através de informações do próprio sistema e as envia através de socket. 
openKnowledg

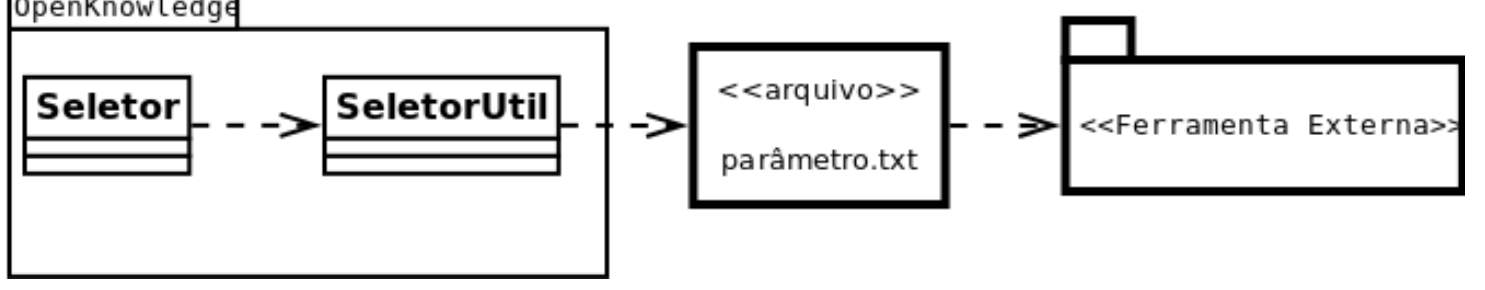

Figura 5.1: Diagrama Selector 


\section{Capítulo 6}

\section{Experimentos}

Utilizando os algoritmos propostos no Capítulo 5, foram montados três cenários com objetivo de verificar a execução de cada um deles. Nos experimentos realizados se considerou os valores de atraso nos serviços disponibilizados e a taxa de perda de pacotes no meio de transmissão, como também a utilização de CPU da máquina que disponibilizava determinado serviço. Utilizou-se apenas mensagens de envio e respostas de mensagens, sem necessidade de grande processamento. Buscou-se variar o tamanho dessas mensagens a fim de utilizar ao máximo a rede onde foi realizada a composição. A obtenção dos valores dos parâmetros foram feitos em tempo de execução, a fim de se conseguir dados atualizados.

O algoritmo escolhido para comparações com o primeiro algoritmo proposto foi o modo default do OK, que se trata de uma abordagem FIFO. O algoritmo GEA 3.4.1 implementado no OK foi descartado da comparação já que utiliza a reputação para selecionar serviços, dessa forma seria uma comparação equivalente a abordagem FIFO pois não foi prevista a verificação de confiabilidade nos experimentos.

Foram montados três cenários para que se pudesse analisar as consequências da seleção de serviços levando em consideração parâmetros de rede e de processamento. No primeiro e no segundo cenário foram considerados o atraso como parâmetro de seleção e no terceiro utilizou-se como parâmetro a perda de pacotes, perda de pacotes juntamente com atraso (utilizando algoritmo $1 \mathrm{e}$ 2), e perda de pacotes e atraso juntamente com taxas de utilização de CPU (utilizando algoritmo $3)$.

\subsection{Experimentos Preliminares}

\subsubsection{Atraso como Parâmetro}

Os experimentos com seleção levando em conta o atraso foram realizados em um computador equipado com um processador Intel(R) Core(TM) i7-2700K (4 núcleos, 8 threads) a 3,5GHz com $8 \mathrm{MB}$ de cache, 16GB de memória RAM e 1TB de HD. Foram realizados experimentos com envio de diferentes quantidades de dados na coreografia: 10MB, 20MB, 30MB, 40MB e 50MB de um serviço A para um serviço B.

\section{Cenário 1}

Os primeiros experimentos foram realizados localmente com 10 (dez) repetições para cada tamanho de dados com o objetivo de verificar o comportamento da coreografia, implementada no framework, e o tempo do algoritmo proposto em relação a abordagem FIFO na seleção de serviços com parâmetros de rede com diferentes quantidade de dados. Os serviços foram acessíveis via o endereço IP (Internet Protocol) da máquina, diferenciando apenas a porta de cada serviço. Nesse caso não era esperado que houvesse diferenças significativas entre o seletor proposto e o mecanismo FIFO padrão do OK, já que não havia uma grande diferença entre as taxas de atraso, por ser uma comunicação local, as taxas de atraso foram em média 0,3 ms. A Figura 6.1 mostra os tempos de 
execução da coreografia quando os serviços foram selecionados pelo seletor proposto e pelo FIFO padrão do OK.

A partir desses experimentos iniciais notou-se que o tempo de execução do algoritmo selector levou no máximo cerca 300 milissegundo a mais em relação ao FIFO. Isso pode ser explicado pelo fato do algoritmo proposto precisar ler informações armazenadas externamente ao OK. Esse experimento foi necessário para verificar o impacto em relação ao tempo de execução do algoritmo proposto, conclui-se que o impacto no tempo total da coreografia não é significando que possa interferir no seu desempenho.

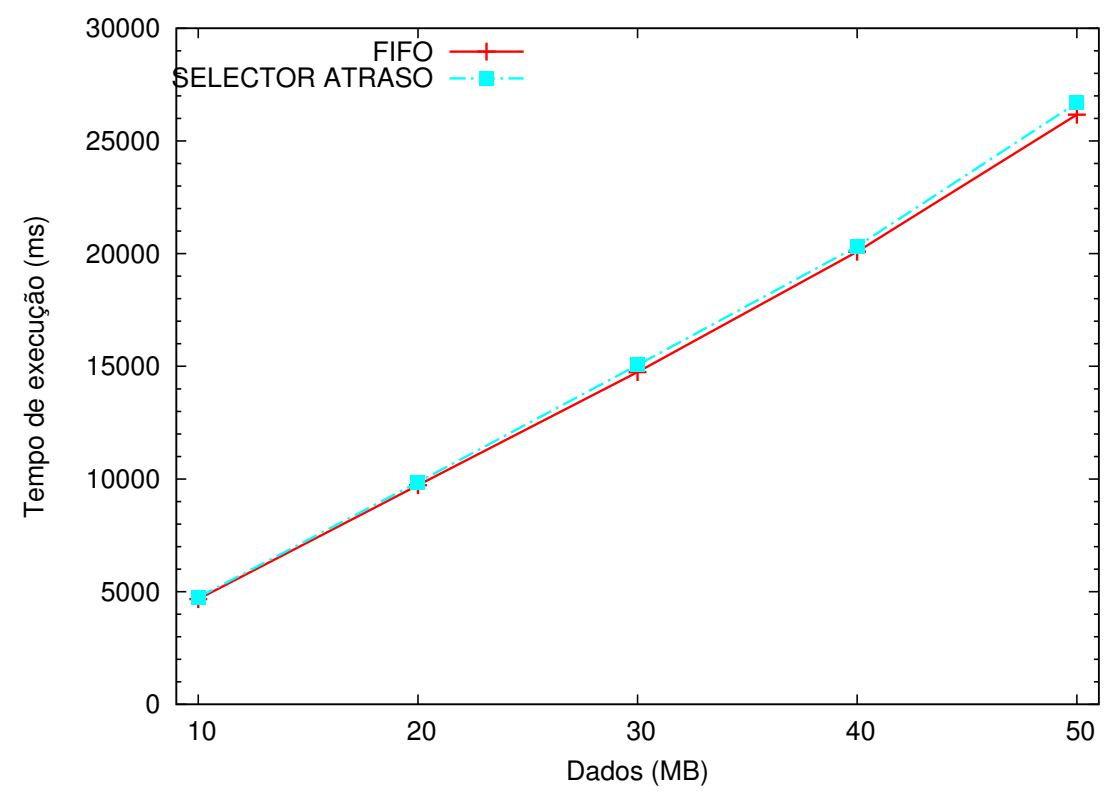

Figura 6.1: Tempo de execução da coreografia - local - atraso como parâmetro de seleção

\section{Cenário 2}

Nos experimentos seguintes, que também considerou atraso para selecionar serviço, foram utilizadas três máquinas virtuais e em cada uma foi colocado um serviço que implementa um mesmo papel. O objetivo foi observar como se dava a escolha de um dos três serviços em máquinas distintas, em um ambiente controlado, porém com variação de valores de atrasos evidentes. Embora as máquinas virtuais estivessem localizadas na mesma máquina real, o kernel das máquinas faz todos os pacotes percorrerem a pilha de protocolos implementada e nesse caso a rede afeta mais a escolha do que o caso anterior, em que os experimentos foram feitos acessando os serviços localmente.

Em dois dos serviços nas máquinas virtuais, utilizou-se a ferramenta TC ( Traffic Control) ${ }^{1}$ para gerar valores de atrasos consideráveis. De três serviços disponibilizados com o mesmo papel, um possuía $20 \mathrm{~ms}$ de atraso, outro possuía $10 \mathrm{~ms}$ e outro, que não foi utilizado a ferramenta TC, possuía média de atraso de 0,4 ms. Foram realizadas 10 (dez) repetições para cada tamanho de dados.

De um modo geral, o ganho obtido a partir de dados com 30MB foram mais evidentes, apresentando diferenças de cerca de 20\%, como mostra a Figura 6.2.

\subsection{Experimentos em uma Rede Real}

\subsubsection{Perda como Parâmetro}

Utilizando o parâmetro atraso é previsível que um serviço que seja escolhido com menor atraso tenha um tempo menor do que um serviço escolhido uma taxa de atraso alta. Dessa forma, os

\footnotetext{
${ }^{1}$ http://www.tldp.org/HOWTO/html_single/Traffic-Control-HOWTO/
} 


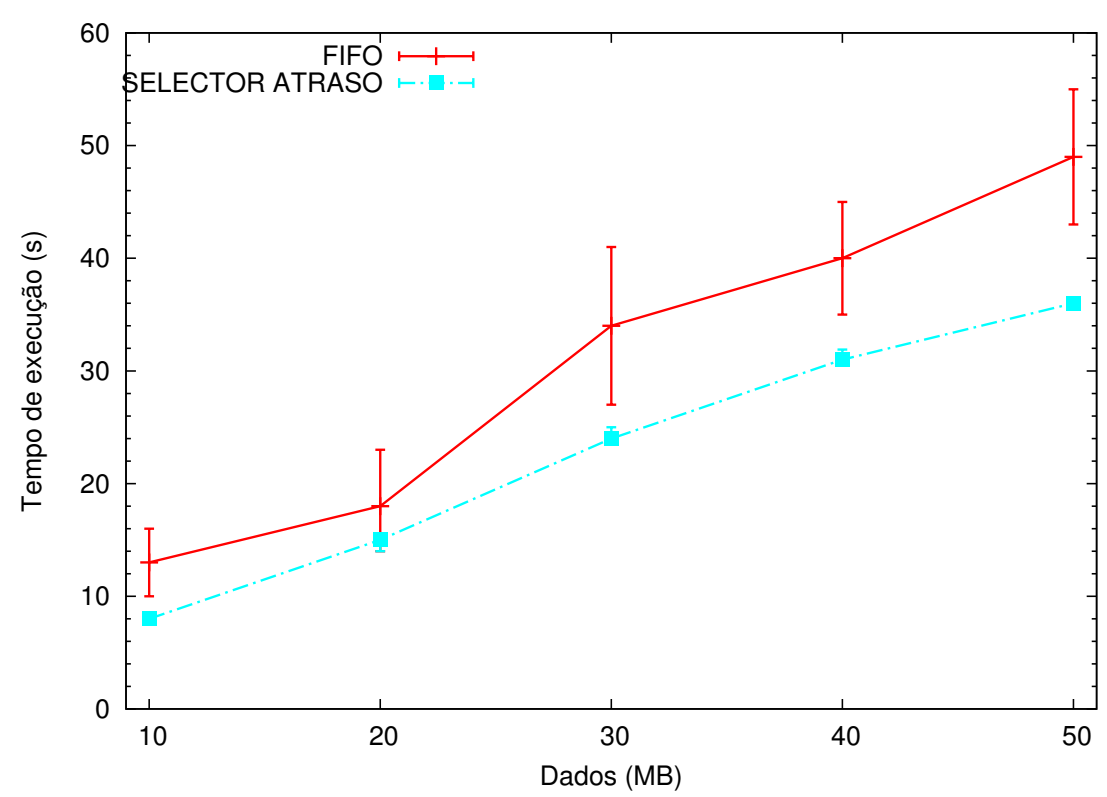

Figura 6.2: Tempo de execução da coreografia - Máquinas Virtuais - atraso como parâmetro de seleção

experimentos anteriores serviram para mostrar o impacto no tempo de execução de uma coreografia caso seja escolhido um serviço que apresente uma taxa de atraso maior em relação a outro serviço que disponibilize o mesmo papel, principalmente ser houver uma grande transferência de dados. No entanto, em cenários reais além do atraso outros problemas relacionados a rede podem ocorrer e afetar a execução de uma coreografia. O algoritmo proposto, implementado no OK, tem a flexibilidade de agregar diversos outros parâmetros de análise sem mudanças bruscas no código principal. Sendo assim, após obter os resultados com atraso buscou-se utilizar outro parâmetro de rede para analisar o comportamento da escolha de serviços. Assim, foi inserido o critério de perda de pacotes.

Nesse etapa escolheu-se um cenário com rede sem fio para realizar os experimentos, dado que nesse cenário as perdas são mais evidentes e é um ambiente mais instável em relação a uma rede cabeada, por exemplo.

Conseguiu-se facilmente níveis significativos de perda, contudo, as variações foram muito grandes em experimentos preliminares. Para auxiliar no controle das perdas entre os serviços utilizou-se a ferramenta TC. Dessa forma, se configurou uma das máquinas que oferecia o serviço que desempenhava o papel que estava sendo buscado para apresentar de $25 \%$ de perda. Devido as especificidades do cenário, essas taxas em certos momentos aumentavam, chegando a taxas de até $75 \%$ de perda. Outro serviço que desempenhava o mesmo papel apresentava taxas significativas de perda de até $50 \%$ em algumas ocasiões, sem necessidade de utilização da ferramenta. E o terceiro serviço com o mesmo papel não apresentava taxas de perda.

\section{Cenário 3}

Nesse cenário para os experimentos com perda foi utilizado um roteador TP-Link modelo TLWR741ND e conectados a ele estavam dois notebooks e um computador de mesa. As configurações dos notebooks são as seguintes:

- Máquina 1 (M1): processador Genuine Intel(R) CPU U4100 (2 núcleos) a 1,30GHz, 3GB de memória RAM e 250GB de HD;

- Máquina 2 (M2): processador Intel(R) Core(TM) i3 CPU M380 (4 núcleos) a 2,53GHz, 4GB de memória RAM e 500GB de HD;

- Máquina 3 (M3): processador AMD Phenom(TM) 8450 Triple-Core Processor (3 núcleos), 4GB de memória RAM e 100GB de HD. 
M2 executava o OK, alguns serviços da coreografia e também uma máquina virtual. As máquinas M1, a máquina virtual de M2 e M3 disponibilizavam um serviço, cada uma, que implementa um mesmo papel, sendo possível o OK (disponibilizado em M2) escolher entre um desses serviços para executar a coreografia.

Foram realizados experimentos enviando diferentes quantidade de dados na coreografia. A capacidade efetiva média de transmissão na rede foi de $27 \mathrm{Mbits} / \mathrm{seg}$ durante todas as medições. Devido a limitação dos computadores usados e da rede, as quantidades de dados transferidos foram 1MB, $2 \mathrm{MB}, 3 \mathrm{MB}, 4 \mathrm{MB}$ e $5 \mathrm{MB}$ (quantidades de dados a partir de $6 \mathrm{MB}$ tornaram o experimento inviável de ser executado devido a limitação das máquinas e da rede). Foram realizadas diversas repetições e destas foram consideradas 10 válidas para serem analisadas. As válidas foram aquelas nas quais a coreografia concluiu sua execução. Essa diferenciação de repetições válidas foi necessária porque em alguns casos utilizando a seleção FIFO, o atraso era tão grande que a coreografia em execução retornava um erro de estouro de temporização e não finalizava.

A Figura 6.3 apresenta os resultados da média de 10 (dez) execuções das 5 (cinco) quantidades de dados que foram enviadas pela rede. As execuções realizadas com FIFO apresentaram tempos bem maiores do que as execuções utilizando o seletor proposto. Para os experimentos no modo FIFO notou-se que quando o serviço escolhido apresentava uma perda significativa, por exemplo, a partir de $50 \%$, ou ocorria um erro que era resolvido pelo OK, que escolhia outra máquina que disponibiliza o serviço, ou a coreografia não completava. Vale observar que não foi o serviço que não foi capaz de completar a coreografia e sim as condições na rede que contribuíram para o insucesso da coreografia.

Condições como essa geraram tempos bastantes discrepantes nas execuções concluídas com o modo FIFO, pois, muitas vezes, eram escolhidos serviços que estavam disponibilizados na máquina que apresentava um percentual de perda muito grande, então o OK escolhia outro serviço devido a uma falha na comunicação e isso acrescentava tempo que refletia no tempo final da coreografia.

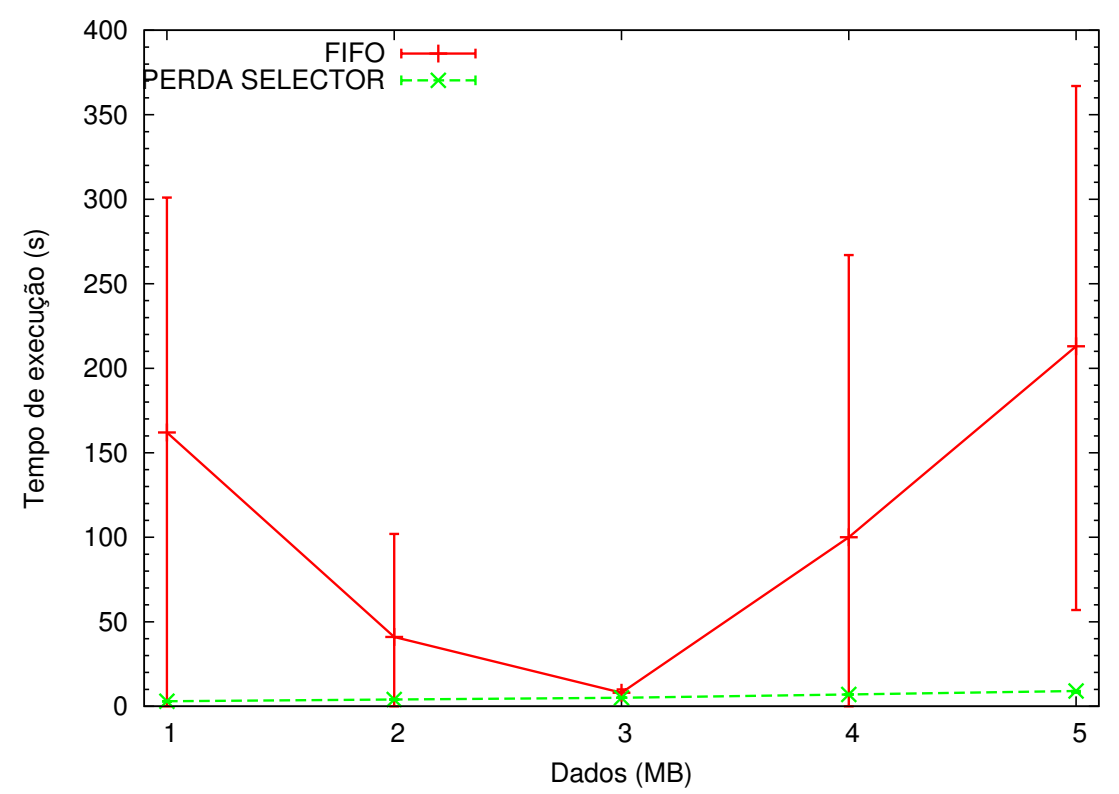

Figura 6.3: Tempo de execução da coreografia - Wifi - perda como parâmetro de seleção

Utilizando o algoritmo de seleção proposto o tempo se manteve estável nas 10 execuções e nenhuma precisou ser descartada, ou seja, todas foram concluídas com êxito. Manteve-se a escolha da máquina que oferecia o serviço e que possuía menor taxa de perda de pacotes. Percebeu-se que a máquina que apresentava perda muitas vezes perdia a conexão com o $\mathrm{OK}$, mas isso não afetava a coreografia, pois ela não era escolhida pelo algoritmo de seleção proposto.

Os resultados obtidos mostraram variação de 35 a $97 \%$ na média do tempo de execução do FIFO em relação ao método proposto considerando perda. Isso pode ser explicado pelo fato de 
o FIFO escolher ora um serviço com boas condições em relação a rede, ora escolher o serviço que apresente piores condições em relação a rede. Dessa forma, podemos concluir a vantagem da utilização de parâmetros relacionados a rede para realizar seleção de serviços em coreografias que demandem uma grande transferência de dados, devido a instabilidade de métodos, como o FIFO, que não verificam a estado da rede, em tempo de execução, antes de realizar a seleção, tanto com seleção considerando perda, como com seleção considerando atraso, apresentadas na seção 6.1.1 que obtiveram ganhos de $20 \%$ no tempo da coreografia.

\subsubsection{Perda e Atraso como Parâmetros}

Após os resultados favoráveis da utilização de perda e atraso como parâmetros procurou-se verificar como se daria a escolha caso utiliza-se os parâmetros de perda e atraso juntos para realizar a seleção. Notou-se nos experimentos com perda que, apesar das escolhas resultarem sempre em médias de tempos mais baixas que o mecanismo que utilizada parâmetros de redes, em alguns casos as escolhas se davam por serviços que tinham a menor perda porém não tinham o menor atraso. Dessa forma, foram agregados os dois parâmetros nos experimentos seguintes utilizando o Cenário 3. A Figura 6.4 apresenta os resultados das médias das 10 (dez) execuções das 5 (cinco) quantidades de dados que foram enviadas na rede, comparadas apenas com o resultados de seleção utilizando apenas perda como parâmetros. Não foram notados médias de tempo tão discrepantes, sendo viável a utilização dos dos parâmetros em conjunto. Porém, a utilização da condicional "E"para selecionar serviços com dois parâmetros de rede se mostrou viável para este cenário, pois havia somente um serviço que apresentava perda, os depois apresentavam perda $0 \%$. A escolha acabou sendo feita pelo que apresentasse menor atraso. Dessa forma, observou esse método inviável para alguns casos.

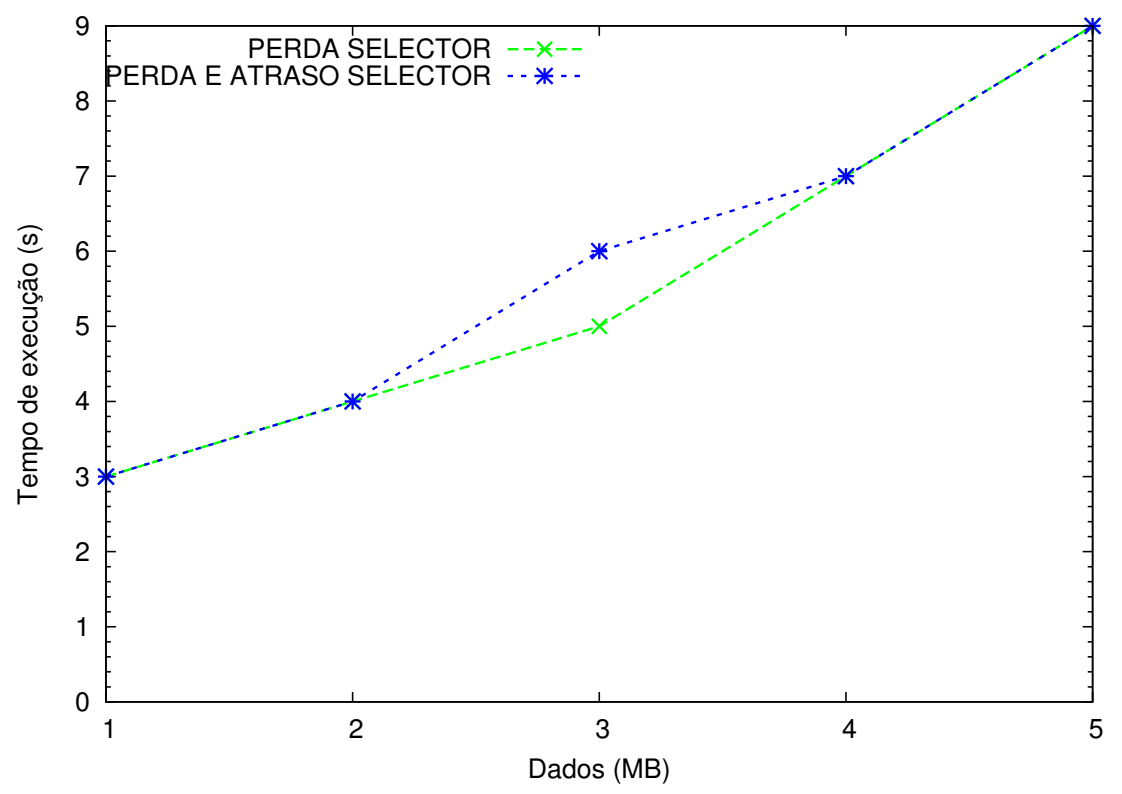

Figura 6.4: Tempo de execução da coreografia - Wifi - perda e perda $\mathcal{E}$ atraso

\subsubsection{Perda, Atraso e CPU como Parâmetros}

Após os resultados favoráveis nos experimentos anteriores (seções 6.1.1, 6.3) a inviabilidade de alguns casos observados no experimento da seção 6.4. Procurou-se realizar os experimentos utilizando o algoritmo baseado em pontuação. Somado a isto, resolve-se avaliar com alguma métrica que não seja de rede. Embora os serviços não sejam $C P U$-intensive, foi inserido também uso de CPU como parâmetro e agregamos com os parâmetros de rede já utilizados.

A utilização de parâmetro de processamento, como monitoramento de CPU, é viável quando a aplicação exige um elevado grau de processamento. Dessa forma, é de fundamental importân- 
cia a opção de utilização desse parâmetro, caso se tenha uma aplicação coreografada com essa característica.

O exemplo utilizado nesse trabalho, entretanto, não requer grandes esforços de processamento, já que envia uma grande quantidade de dados e recebe apenas uma mensagem de confirmação. O processamento exigido está apenas no envio de resposta. Então, o exemplo utilizado está focado em parâmetros de desempenho relacionado ao meio de transmissão. Devido a isto, procuramos inserir parâmetros de analise de CPU, porém com análise de perda e atraso também para fazer a seleção de serviços.

As Figuras 6.5, 6.6, 6.7, 6.8 e 6.9 apresentam os resultados obtidos em cada uma das 5 (cinco) quantidades de dados utilizadas a partir de 10 (dez) repetições de testes realizados no Cenário 3, comparados com as demais abordagem apresentadas, Perda e Perda \& Atraso. Os resultados mostraram tempos próximos aos obtidos utilizando as demais abordagens. Não era esperado de fato ter diferença nos experimentos pelo fato apenas ocorrer a transferência dados e o serviço não realiza nenhum processamento na máquina, porém foi uma forma de mostrar que é possível a inserção de outros parâmetros no método proposto utilizando escolha através de pontuação.

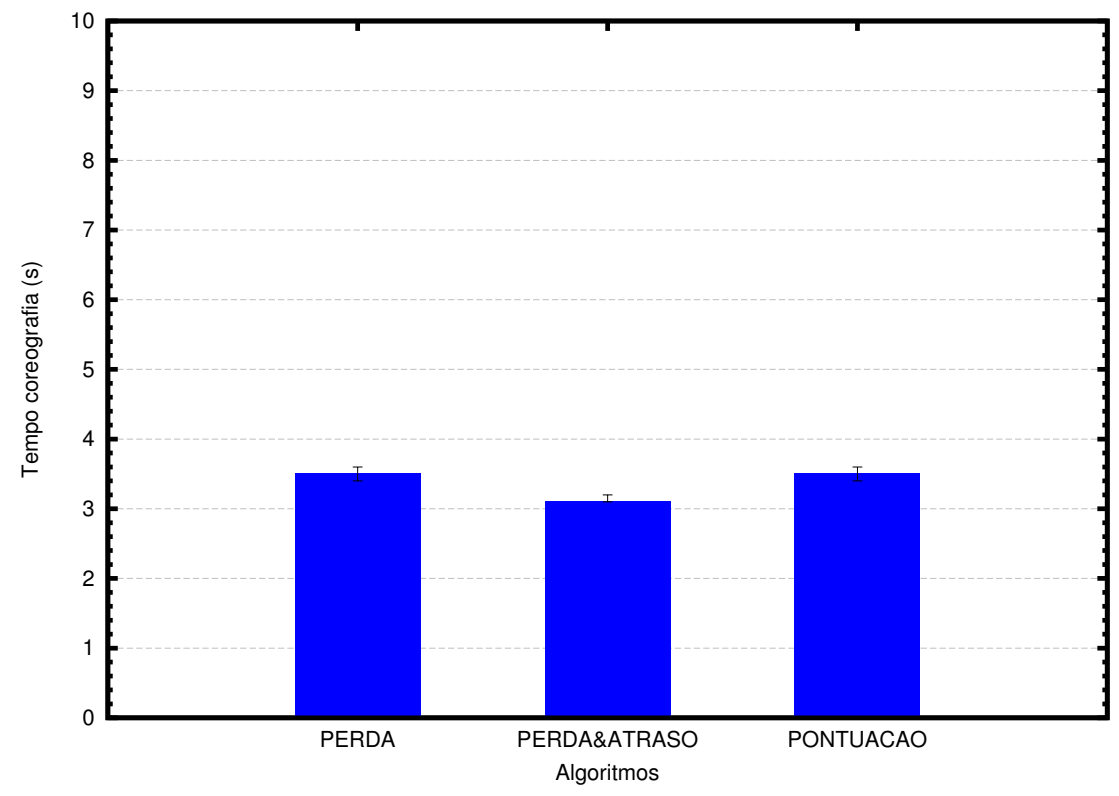

Figura 6.5: Tempo de execução da coreografia Selector $1 M B$

\subsection{Discussão dos resultados}

Os resultados podem ser separados em dois momentos:

1. O experimento realizado primeiramente com o algoritmo de comparação, utilizando um parâmetro de seleção, mostrou a viabilidade da utilização um mecanismo de seleção de serviços que considera parâmetro de rede em detrimento abordagem, que não se preocupa com rede no momento de selecionar serviços. Atrasos em apenas um serviço que compõe a coreografia pode afetar consideravelmente a composição como um todo, como pode ser visto nos resultados. $\mathrm{O}$ resultado mostra de forma favorável que mesmo o algoritmo utilizando comparação direta de valores de atraso ou perda pode ser eficaz resultando em um melhor tempo de execução de coreografias quando há problemas relacionados ao meio de transmissão.

2. A partir das conclusões favoráveis com a primeira fase do trabalho, a proposta se encaminhou para o desenvolvimento de uma solução que fosse capaz de suportar não apenas um parâmetro de seleção. Dessa forma, após a conclusão de que o algoritmo de comparação não é eficaz na 


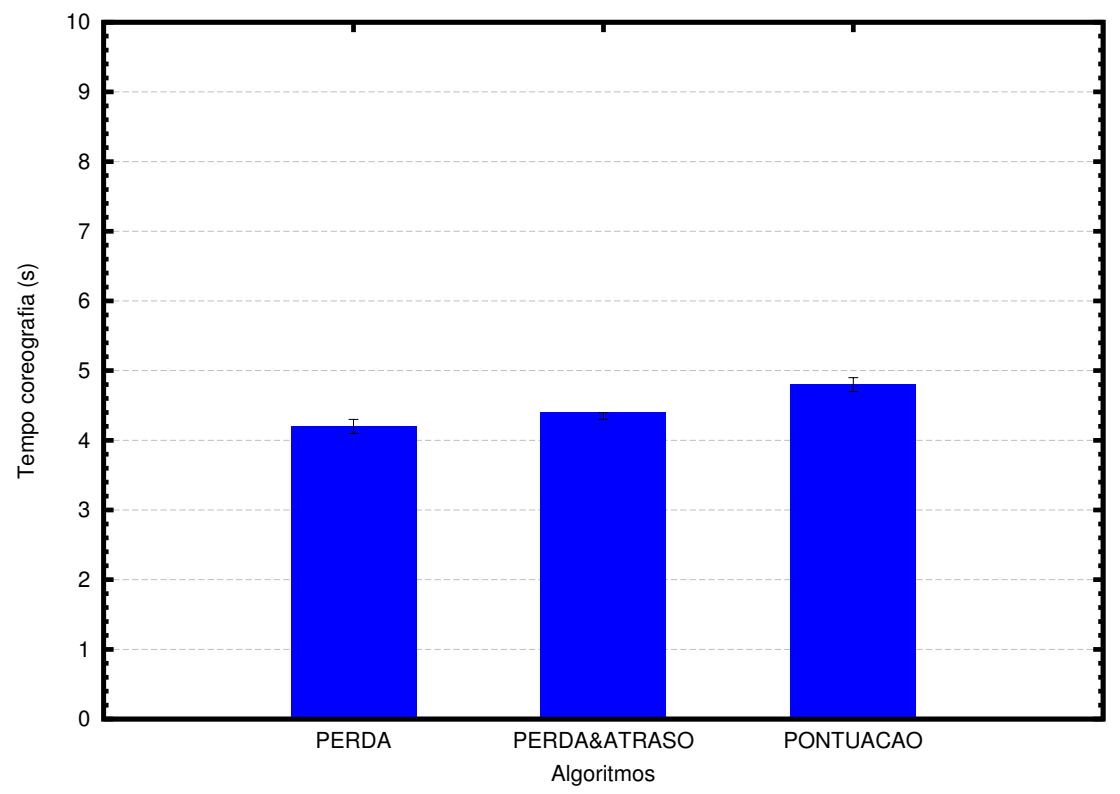

Figura 6.6: Tempo de execução da coreografia Selector $2 M B$

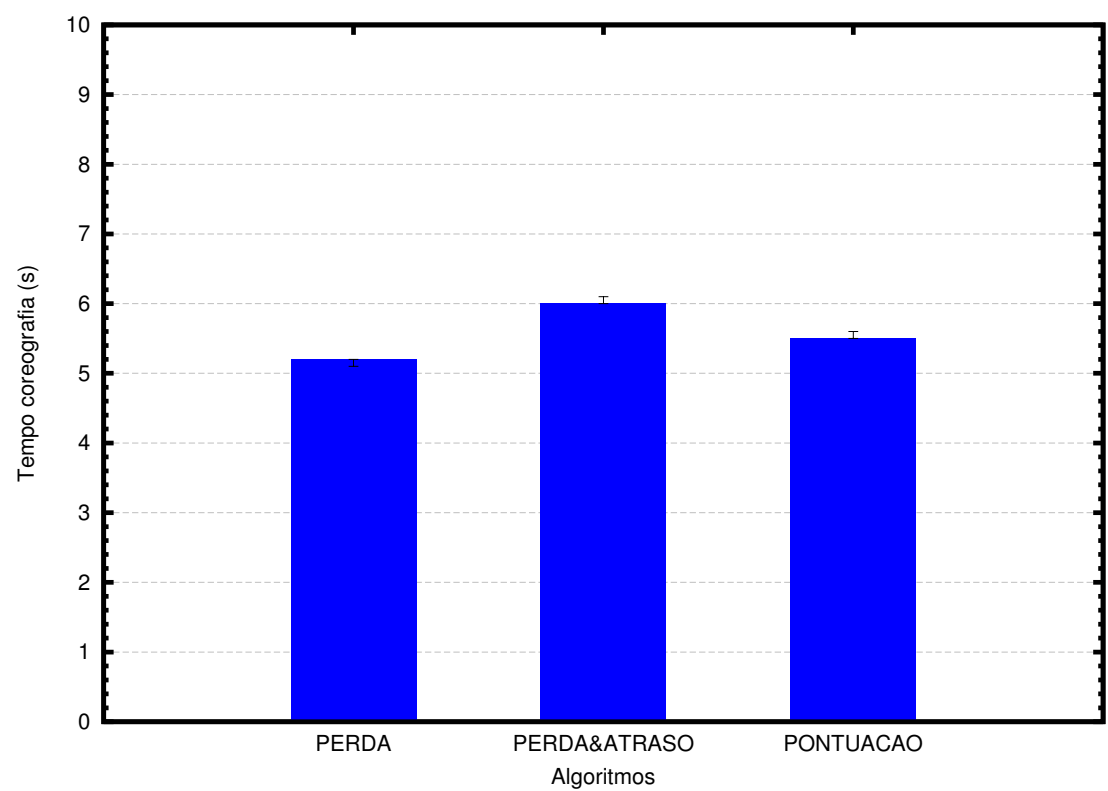

Figura 6.7: Tempo de execução da coreografia Selector 3MB

utilização de múltiplos parâmetros o trabalho se encaminhou para a implementação de um algoritmo baseado em pontuação para selecionar serviços, possibilitando, assim, a utilização de dois ou mais parâmetros conjuntamente para realização da seleção de serviços. Os resultados dessa etapa do trabalho se mostram favoráveis já que os tempo de execução utilizando esse algoritmo em comparação com a proposta inicial se mostram similares, tendendo até em uma maior redução nos tempos de execução quando considerados maiores tamanho de dados enviados pela rede. Nesses experimentos não foi possível a utilização de máquinas que possuíam uma grande sobrecarga, dessa forma não foi possível a analisar de fato o impacto da utilização do parâmetro de CPU nos experimentos. A grande contribuição dessa fase do trabalho se dá a possibilidade de inserção de quais parâmetros para realização de seleção de serviços de forma conjunta sem afetar a execução da coreografia e possibilitando grande ganhos nos tempos de execução. 


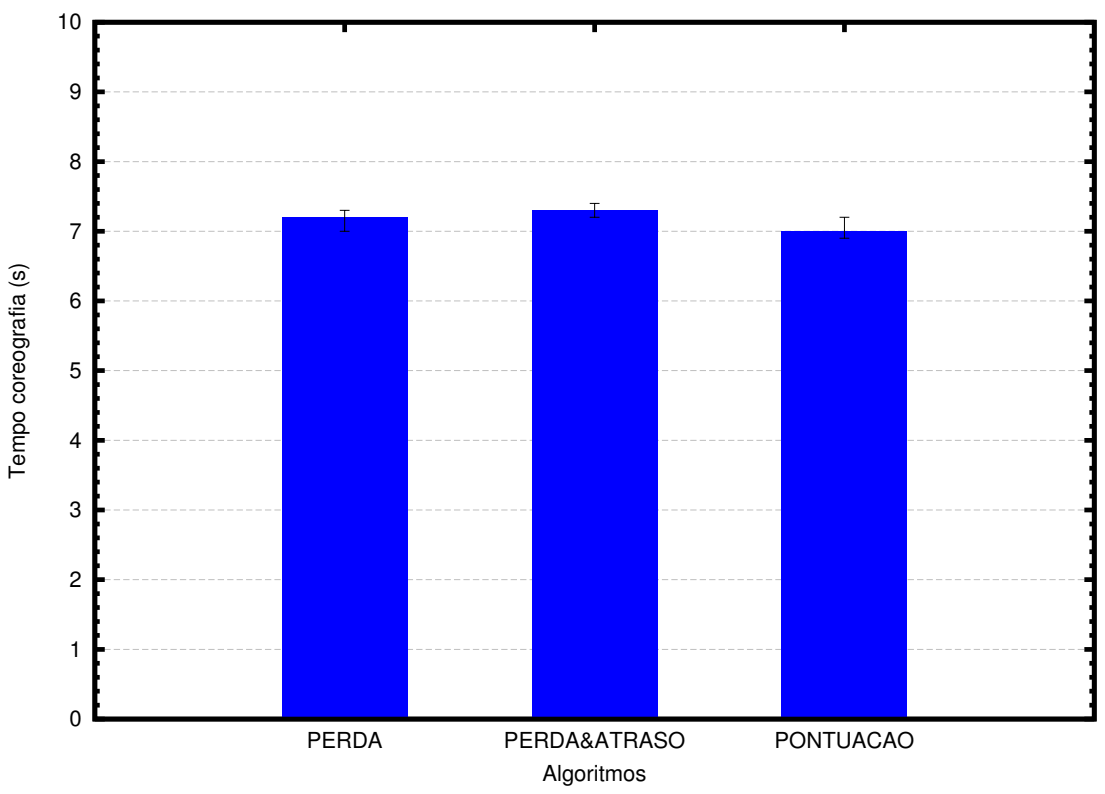

Figura 6.8: Tempo de execução da coreografia Selector $4 M B$

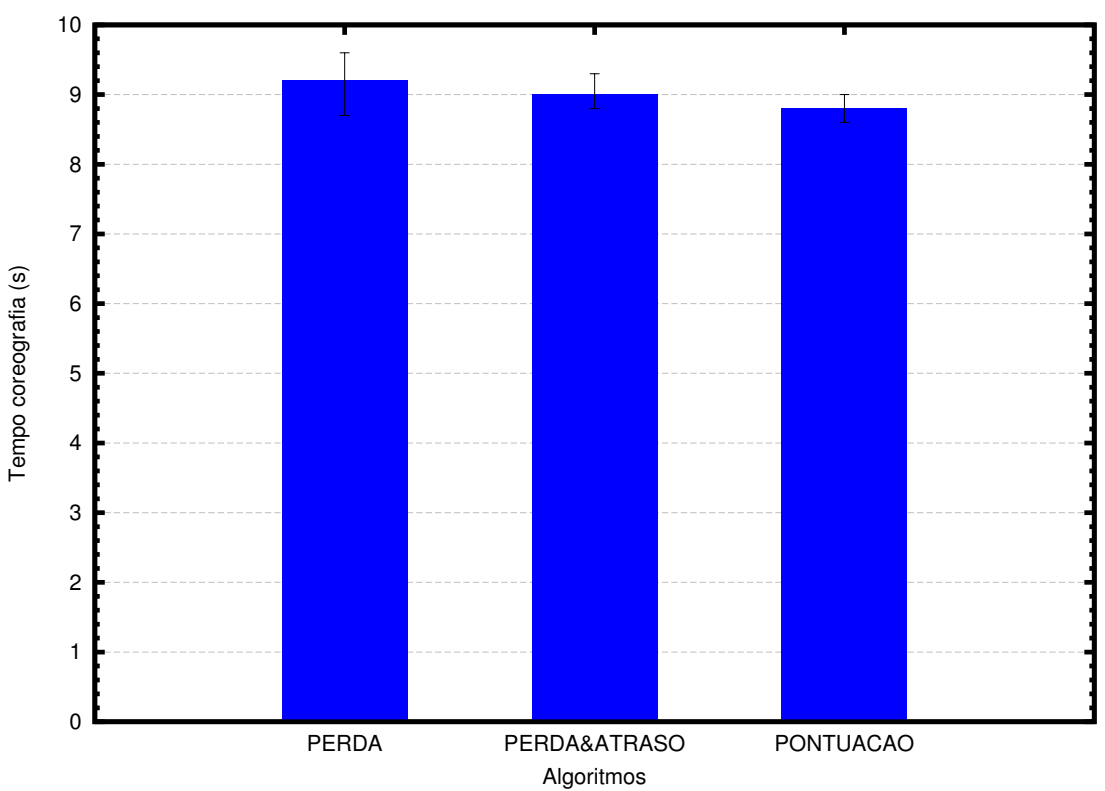

Figura 6.9: Tempo de execução da coreografia Selector 5MB

\subsection{Selector \& GEA}

O algoritmo GEA não foi utilizado nos experimentos deste capítulo, pois ele necessita de informações históricas de confiança, que não foi considerada nos experimentos realizados. Por exemplo, havia a necessidade de informações sobre a capacidade do serviço em selecionado corretamente o papel no qual se inscreveu. Nos experimentos realizados isso não foi relevante, pois tomou-se como base que todo serviço era capaz de desempenhar o papel o qual se inscreveu.

Somado a isto, o GEA necessita de informações da pontuação correspondente do serviço, calculado conforme apresentado no capítulo 3, que, diferente da abordagem feita neste trabalho, diz respeito à pontuação dada por usuário ou outros serviços que o utilizaram o serviço em questão anteriormente.

Seguindo a abordagem de pontuações foi desenvolvido o método de escolha utilizando perda, atraso e utilização de CPU como parâmetro, apresentado na seção 5.0.4. O GEA utiliza a abordagem 
de escolher o serviço com maior pontuação combinando a pontuação de confiança e a pontuação correspondente do serviço dada por usuário ou outros serviços. É possível realizar experimentos utilizando a abordagem apresentada nesse trabalho com o GEA, obtendo pontuações de confiança e, ao invés da pontuação obtida através de usuários ou serviços, pode-se utilizar a pontuação obtida pelo Selector, como pontuação correspondente para definir os serviços que seriam selecionados. 


\section{Capítulo 7}

\section{Conclusões}

Este trabalho apresentou uma proposta de seleção de serviços para desempenhar papéis em coreografias levando em consideração parâmetros de rede e de processamento. Primeiramente, os algoritmos implementados, mesmo que simples, mostraram-se eficientes em relação à política de seleção de serviços padrão disponibilizada pelo framework OpenKnowledge quando comparadas com seleção levando em consideração o atraso e a taxa de perda entre as máquinas que executam esses serviços. Em seguida, a implementação desses algoritmos foi modificada para que novas políticas sejam avaliadas e foi proposto um mecanismo que realiza seleção através de pontuação que se obtém analisando os parâmetros propostos e pontuando cada serviço de acordo com categorias predefinidas. A implementação da proposta no OK representa uma importante contribuição deste trabalho dado que trabalhar com esse framework não é trivial devido sua complexidade.

\subsection{Considerações finais}

Como resultado deste trabalho obteve-se um menor tempo de execução em coreografias em relação ao tempo que elas teriam caso o seletor padrão do OK fosse utilizado, o que mostra que há ganhos em se avaliar os parâmetros de rede e processamento no momento de selecionar os serviços para coreografias. A escolha do OK para implementação da proposta foi puramente prática. Qualquer forma de implementação de coreografia é válida para o bom funcionamento da proposta.

Qualquer ferramenta capaz de obter informações que possam ser utilizadas como parâmetros podem ser usadas e agregadas ao framework a partir de então para realizar a seleção de serviços em coreografias. Dessa forma, a grande contribuição do trabalho se dá no fato de utilizar o framework OK para realização de seleções de serviços em coreografias a partir de parâmetros obtidos de ferramentas externas.

Outra grande contribuição para academia foi mostrar que seleção de serviços em coreografias utilizando parâmetros de rede obtêm resultados significativos comparado com mecanismos que não se preocupam com a rede no momento da seleção em coreografias, evitando problemas em relação ao tempo de execução, já que tempo de execução é um ponto crucial em muitas aplicações de serviços web, especialmente em composição de serviços. Em consequência, a inserção de outros parâmetros e a inserção de pontuação de serviços a partir da análise desse parâmetros em tempo real que vão auxiliar a escolha de serviços em coreografias, foi outra grande contribuição deste trabalho.

\subsection{Sugestões para pesquisas futuras}

Realizar os experimentos em cenários maiores, pois estima-se que a vantagem do mecanismo proposto será cada vez mais evidente. Há a possibilidade de inserção de novos parâmetros para realizar a seleção podendo adaptar para cada necessidade e especificidade de cada cenário. Além disso, a inserção de proposta de uma hierarquia de seleção e histórico de medições de parâmetros, com uma lista de serviços com menor pontuação para a maior pode ser viável caso haja algum problema na seleção do primeiro serviço escolhido a partir de um histórico dessas medições. A 
realização dos experimentos utilizando dispositivos móveis também é possível. E por fim, utilizar o mecanismo proposto em outras ferramentas que implementem coreografias e utilização juntamente com outros algoritmos de seleção de serviços, como GEA, é possível e pode ser de grande valia para trabalhos futuros. 


\section{Referências Bibliográficas}

[ARDS $\left.{ }^{+} 11\right]$ M. Autili, D. Ruscio, A. Di Salle, N. Georgantas, S. Hachem, V. Issarny, A. Parathyras, L. Trimintzios, D. Silingas, J. Lockerbie, N. Maiden, A. Ben Hamida, A. Bertolino, G. De Angelis, A. Polini, D. Athanasopoulos e A. Zarras. Choreos perspective on the fi and initial conceptual model, 2011. Deliverable D1.2, CHOReOS. Disponível em http://www.choreos.eu/bin/Download/Deliverables. Último acesso em 3 de Abril de 2014. 8

$\left[\mathrm{BBM}^{+} 08\right]$ Matteo Baldoni, Cristina Baroglio, Alberto Martelli, Viviana Patti e Claudio Schifanella. Service selection by choreography-driven matching. Em Thomas Gschwind e Cesare Pautasso, editors, Emerging Web Services Technology, Volume II, Whitestein Series in Software Agent Technologies and Autonomic Computing, páginas 5-22. Birkhauser Basel, 2008. 2, 21

[BBRW09] A. Barker, P. Besana, D. Robertson e J.B. Weissman. The benefits of service choreography for data-intensive computing. Em Proceedings of the 7th international workshop on challenges of large applications in distributed environments, páginas 1-10. ACM, 2009. xi, 1, 2, 7, 8, 12, 21

[BL06] M. Bichier e K.J. Lin. Service-oriented computing. Computer, 39(3):99-101, 2006. xi, 5,6

$\left[\mathrm{BPB}^{+}\right.$09] P. Besana, V. Patkar, A. Barker, D. Robertson e D. Glasspool. Sharing choreographies in OpenKnowledge: A novel approach to interoperability. Journal of Software, 4(8):833-842, 2009. 21

[DKB08] Gero Decker, Oliver Kopp e Alistair P. Barros. An introduction to service choreographies (Service choreographien - eine einfuhrung). it - Information Technology, 50(2):122-127, 2008. 7

[Erl04] T. Erl. Service-oriented architecture. Prentice Hall, 2004. 5

[FK10] E. Francesquini e F. Kon. Orquestração e coreografias de serviços web, 2010. Apresentação Congresso Brasileiro de Software. Disponível em http://www.ime.usp.br/ emilio/ presentations/cbsoft2010.pdf. Último acesso em 30 de Janeiro de 2013. 8

$\left[\mathrm{FPA}^{+}\right.$09] C. Furtado, V. Pereira, L. Azevedo, F. Baião, F. Santoro, A. Magdaleno, C. Capelli e V. Nunes. Arquitetura orientada a serviço - conceituação, 2009. Relatórios Técnicos do DIA/UNIRIO (RelaTe-DIA), RT-0012/2009. Disponível em http://www.seer.unirio. br/index.php/monografiasppgi/article/view/266/267. Último acesso em 30 de Janeiro de 2013. 5

[GKB12] F. Guimarães, E. Kuroda e D. Batista. Performance evaluation of choreographies and orchestrations with a new simulator for service compositions. Em CAMAD 2012International Workshop on Computer-Aided Modeling Analysis and Design of Communication Links and Networks, páginas 140-144, 2012. xi, 1, 7, 8 
[GPB07] F. Giunchiglia, J. Pane e P. Besana. Specification of the good enough answer component, 2007. Deliverable D3. 5, OpenKnowledge. Disponível em http://eprints.biblio. unitn.it/1349/1/techRep005.pdf. Último acesso em 31 de Janeiro de 2013. xi, 17

$\left[\mathrm{GSM}^{+}\right.$07] F. Giunchiglia, C. Sierra, F. McNeill, N. Osman e R. Siebes. Good enough answer algorithms, 2007. Deliverable D4.5, OpenKnowledge. Disponível em http://www.cisa. inf.ed.ac.uk/OK/Deliverables/D4.5.pdf. Último acesso em 30 de Janeiro de 2013. 2, 16

$\left[\mathrm{HHY}^{+}{ }^{12}\right]$ Qiang He, Jun Han, Yun Yang, Jean-Guy Schneider, Hai Jin e Steven Versteeg. Probabilistic critical path identification for cost-effective monitoring of service-based systems. Em Louise E. Moser, Manish Parashar e Patrick C. K. Hung, editors, IEEE SCC, páginas 178-185. IEEE, 2012. 20, 22

[HL13] San-Yih Hwang e Chien-Hsiang Lee. Reliable web service selection in choreographed environments. Decis. Support Syst., 54(3):1463-1476, Fevereiro 2013. 2, 21

[HXZ ${ }^{+}$06] Yang Hongli, Zhao Xiangpeng, Qiu Zongyan, Pu Geguang e Wang Shuling. A formal model of web service choreography description language(ws-cdl). Relatório técnico, 2006. 7

[Kre03] H. Kreger. Fulfilling the web services promise. Communications of the ACM, 46(6):29ff, 2003. 6

[KS] S. Kotoulas e R. Siebes. Adaptive routing in structured peer-to-peer overlays. Deliverable D2.2, Technical report, OpenKnowledge. Disponível em http://www.cisa.inf.ed. ac.uk/OK/Deliverables/D2.2.pdf. Último acesso em 20 de Novembro de 2013. 11

[Lea04] Yutu Liu e et al. Qos computation and policing in dynamic web service selection. Em WWW2004, páginas 66-73. ACM Press, 2004. 2, 19

[MB06] E.A. Marks e M. Bell. Service Oriented Architecture (SOA): A Planning and Implementation Guide for Business and Technology. Wiley, 2006. 5

[MF07] P.H. Michels e R. Fileto. Coreografia de serviços web (uma abordagem para a integração de serviços web), 2007. Barchelor's work of Universidade Federal de Santa Catarina. 6

[MSHR10] Sasa Misailovic, Stelios Sidiroglou, Henry Hoffmann e Martin Rinard. Quality of service profiling. Em Proceedings of the 32Nd ACM/IEEE International Conference on Software Engineering - Volume 1, ICSE '10, páginas 25-34, New York, NY, USA, 2010. ACM. 20

[MTDL08] P.P. Michael, P. Traverso, S. Dustdar e F. Leymann. Service-oriented computing: a research roadmap. International Journal of Cooperative Information Systems, 17(02):223255, 2008. 1,6

[PDKS07] A. Pinninck, D. Dupplaw, S. Kotoulas e R. Siebes. The openknowledge kernel. Em World Academy of Science, Engineering and Technology, number 27, 2007. 13, 14, 15, 16

[Pel03] C. Peltz. Web services orchestration and choreography. Computer, 36(10):46-52, Oct 2003. 7

[PVDH07] M.P. Papazoglou e W.J. Van Den Heuvel. Service oriented architectures: approaches, technologies and research issues. The VLDB journal, 16(3):389-415, 2007. 6

[RM14] Rene Ramacher e Lars Monch. Robust multi-criteria service composition in information systems. Business 8$\}$ Information Systems Engineering, páginas 1-11, 2014. 20 
[Rob05] David Robertson. A lightweight coordination calculus for agent systems. Em JoÂ£o Leite, Andrea Omicini, Paolo Torroni e pInar Yolum, editors, Declarative Agent Languages and Technologies II, volume 3476 of Lecture Notes in Computer Science, páginas 183-197. Springer Berlin Heidelberg, 2005. 12, 13

[VIG $\left.{ }^{+} 10\right]$ H. Vincent, V. Issarny, N. Georgantas, E. Francesquini, A. Goldman e F. Kon. Choreos: scaling choreographies for the internet of the future. Em Middleware'10 Posters and Demos Track, página 8. ACM, 2010. 1, 2

$\left[\mathrm{ZBD}^{+}\right.$03] Liangzhao Zeng, Boualem Benatallah, Marlon Dumas, Jayant Kalagnanam e Quan Z. Sheng. Quality driven web services composition. Em Proceedings of the 12th International Conference on World Wide Web, WWW '03, páginas 411-421, New York, NY, USA, 2003. ACM. 2, 19 